\title{
Instagram, \\ Beden ve Benliğin Sunumu: Erkek Kişisel Antrenörler Örneği
}

Başvuru Tarihi: 10.10 .2021 Yayın Kabul Tarihi: 20.12 .2021 Yayınlanma Tarihi: 30.12 .2021

\section{Deniz Benzer ${ }^{1}$}

Beykent Üniversitesi, Iletişim Fakültesi, Yeni Medya Bölümü, Istanbul denizbenzer@beykent.edu.tr iD ORCID: 0000-0001-7365-9517

\section{Figen Ünal Çolak ${ }^{2}$}

Anadolu Üniversitesi, Illetişim Bilimleri Fakültesi, Iletişim Tasarımı ve Yönetimi Bölümü, Eskişehir fiunal@anadolu.edu.tr

iD ORCID: 0000-0002-8854-6432

\section{öz}

Günümüz toplumsal dinamikleri modern çağdan oldukça farklıdır. Kimlik ve benlik sunumu bu farklılığın en açık hissedildiği alanlardan biridir. Modern süreçte Weber'in demir kafesine hapsolan birey, günümüzde özgürlüğüne kavuşmuş ancak bu sefer de çeşitli tüketim göstergeleri aracılığı ile kimliğini sürekli yeniden inşa etmek zorunda kalmıştır. Bu süreçte geleneksel medya izleyiciye benimseyebileceği çeşitli kimlik kalıpları sunarken sosyal medya ise seçilen kimlikleri aktör olarak oynayabilme imkânı sağlamaktadır. Nitekim beden de bu süreçte sahibine çeşitli avantajlar ve dezavantajlar sunan, 'formda' tutulması gereken bir nesne hali alarak popüler kimlik alternatiflerinden biri haline gelmiştir. Çalışma temel olarak, toplumsal alanda bedensel sermayelerini öne çıkaran kişisel antrenörlerin Instagram'da izledikleri stratejileri betimlemeyi amaçlamaktadır. Nitel olarak desenlenen bu araştırmada, 8 kişisel antrenörün 49 fotoğrafı Barthes'ın göstergebilim yaklaşımı ile okunmuş, Bourdieu ve Goffman'ın terimleri ile tablolaştırılmıştır. Sonrasında ise antrenörlerin stratejileri tablodaki veriler ve incelenen fotoğrafların altına yazdıkları metinler referans alınarak Wacquant'ın bedensel sermaye kavramı ve Bourdieu'nun sosyolojik yaklaşımı ile değerlendirilmiştir. Araştırmanın bulguları göstermektedir ki, kaslı bedene sahip olmak, Instagram 'alanında' popüler bir antrenör olabilmek için zorunludur. Kültürel sermaye, kişisel antrenörlere bedensel sermayelerini ekonomik sermayeye dönüştürebilme konusunda çeşitli avantajlar sağlamaktadır ve habitus kültürel sermayenin önemli bir belirleyicisidir. Gerekli kültürel sermayeye sahip olmayan antrenörler ise bu eksikliği farklı stratejilere başvurarak kapatmaya çalışmaktadır.

Anahtar Kelimeler: Bedensel sermaye, habitus, kişisel antrenör, benliğin sunumu, instagram.

\footnotetext{
${ }^{1}$ Araştırma Görevlisi

2 Doçent Doktor
} 


\title{
Instagram, Body and Self Presentation: Example of Male Personal Trainers
}

\section{Deniz Benzer ${ }^{3}$}

Beykent University, Faculty of Communication, Department of New Media, istanbul

denizbenzer@beykent.edu.tr

ORCID: 0000-0001-7365-9517

Figen Ünal Çolak ${ }^{4}$

Anadolu University, Faculty of Communication Sciences, Communication Design and Management, Eskişehir

fiunal@anadolu.edu.tr

iD ORCID: 0000-0002-8854-6432

\begin{abstract}
Today's social dynamics are quite different from the modern age. Identity and self-presentation is one of the issues in which this difference is most clearly felt. In the modern process, the individual trapped in Weber's iron cage is freed today, but has to constantly reconstruct his/her identity through various consumption indicators. In this process, while traditional media offers the audience various identity patterns that they can adopt, social media provides the opportunity to play the chosen identities as an actor. As a matter of fact, the body has become one of the popular identity alternatives by becoming an object that needs to be kept in 'fit', offering various advantages and disadvantages to its owner in this process. The study basically aims to describe the strategies followed by personal trainers who emphasize their bodily capital on Instagram. In this qualitative study, 49 photographs of 8 personal trainers were read with Barthes' semiotic approach and tabulated in Bourdieu and Goffman's terms. Afterwards, the strategies of the coaches were evaluated with Wacquant's concept of bodily capital and Bourdieu's sociological approach, using the data in the table and the captions of the examined photographs. The findings of the study show that having a muscular body is essential to be a popular trainer in the Instagram 'space'. Cultural capital provides personal trainers with various advantages in transforming their physical capital into economic capital, and habitus is an important determinant of cultural capital. Coaches who do not have the necessary cultural capital try to make up for this deficiency by applying different strategies.
\end{abstract}

Keywords: Bodily capital, habitus, personal trainer, self-presentation, instagram.

\footnotetext{
${ }^{3}$ Research Assistant

${ }^{4}$ Associate Professor
} 


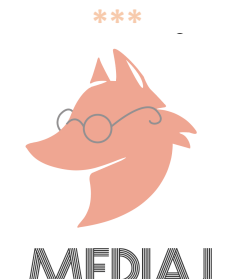

\section{Giriş}

Günümüz toplumsal dinamikleri modern çağa göre büyük farklılıklar arz etmektedir. Bu dönüşümün en keskin olduğu alanlardan biri kimlik ve benlik sunumu meselesidir. Modern süreçte Weber'in demir kafesine hapsolan birey, günümüzde bu kafesten kurtulmuş ancak 'mükemmelliğinin sonunun gelmiş olması' (Bauman, 2017) nedeni ile kendini tüketim göstergeleri aracılı̆̆ı ile sürekli yeniden inşa etmek zorunda kalmıştır (Hall, 2000). Medya, kimlik algısı ve tüketim matrisinde hangi göstergelerin seçileceği konusunda kritik bir öneme sahiptir (McLuhan, 2014; Debord, 2014). Yeni medya teknolojileri ve sosyal medya ise buna ek olarak kullanıcılara benimsenen kimlikleri sergileme imkânı da sağlamaktadır. Bu grift ilişkiden en çok etkilenen mefhumlardan biri bedendir. Günümüzde beden de kimliğe benzer bir şekilde spor, diyet, estetik operasyon gibi yöntemler ile sürekli yenilenerek dönüştürülen bir proje (Shilling, 1993), toplumsal ilişkilerde avantaj elde etme ya da dezavantajlı konuma düşmeyi sağlayan bir sermaye (Wacquant, 19995) ve gösterge (Featherstone, 2010) haline gelmiştir. Araştırma, bu bağlamda Bourdieu'nun (Bourdieu, 1986; Bourdieu ve Wacquant, 2003) sosyolojik kavramlarını referans alarak vücut geliştirme ve fitness alanında uzaktan eğitim veren erkek kişisel antrenörlerin sahip olduğu bedensel sermayeyi Instagram'da nasıl kullandıklarını Goffman'ın (2014) dramaturjik yaklaşımı ile betimlemeyi amaçlamaktadır.

Uluslararası alanda bedensel sermaye ile ilgili oldukça geniş bir literatür bulunmaktadır. Bedensel sermaye kavramının ortaya çıkmasını sağlayan Wacquant'ın (1995) boksörler ile ilgili yaptığı etnografik çalışma, Shilling'in (1993) bedenin nasıl bir projeye dönüştüğünü ele aldığı Beden ve Sosyal Teori (Body and Social Theory) eseri, Stewart, Smith, ve Moroney'nin (2013) proje beden ve bedensel sermayenin birbirini tamamlayıcı özelliklerini, Johansson ve Andreasson (2016) fitness - küreselleşme ilişkisini, Mears'in (2015) kadınların bedensel sermayeleri ve VIP partilere katılabilme olasılığını, Harvey, Vachhani ve Williams'ın (2014) duygusal emek bağlamında kişisel antrenörleri, Hutson'ın (2013) kişisel antrenörler ve bedensel sermaye ilişkisini, George' un (2008) post-endüstriyel emek - kişisel antrenörler arasındaki ilişkiyi, Maguire'ün (2008) kişisel antrenörlük ilanlarını, Frew ve McGillivray'nin (2005) bedensel sermaye - kapitalizm ilişkisini, Anderson ve diğerlerinin (2001) doktorların fiziksel görünümleri ve hastaların üzerindeki otoritesini, Sasatelli'nin (1999) spor salonlarına gitme ve kimlik inşası arasındaki ilişkiyi ele aldığı çalışmalar bunlara örnek verilebilir. Ancak bu geniş literatüre karşın Türkiye'de bedensel sermayeye odaklanan çalışmalar oldukça kısıtıdır. Çarpar ve Gönç Şavran'ın (2019) vücut geliştirme alanının eril pratikleri nasıl yeniden ürettiğini; Karaçam ve Koca'nın (2016) vücut geliştirmenin erkekler arasında nasıl bir hiyerarşi oluşturduğunu; Emir, Karaçam ve Koca'nın (2015) kadın boksörlerin deneyimlerine odaklandığı çalışmalar bu bağlamda değerlendirilebilir. Ancak bu çalışmaların hepsi bedensel sermayeyi toplumsal cinsiyet kapsamında tartışmaktadır. Bu çalışma, antrenörlük rolüne ve Instagram üzerindeki sunumlara odaklanması yönüyle özgünlük taşımakta ve diğer çalışmalardan ayrılmaktadır.

Bedensel sermayenin aksine, Goffman'ın dramaturjik yaklaşımını sosyal medya bağlamında ele alan hem ulusal hem de uluslarası birçok çalışma bulunmaktadır. Donath'ın (1998) kullanıcıların yeni medya kanallarında gerçek kimliklerine benzer temsilleri sunduğunu ve Goffman'ın dramaturjik yaklaşımının sanal dünyalarda uygulanabileceğini öne sürdüğü çalışma, Goffman'ı yeni medyaya/soyal medyaya uyarlayan ilk çalışmalardan biri olarak nitelenebilir. Goffman'ın 


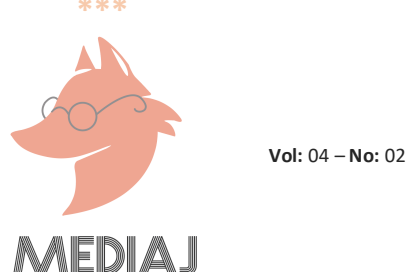

yaklaşımını ve kavramlarını ilk defa kullanması ya da farklı bir bakış açısı ile değerlendirmesi yönüyle ele alan birçok çalışma mevcuttur (Hogan, 2010; Lewis, Kaufman, ve Christakis, 2008; Hewitt ve Forte, 2006; Donath ve Boyd, 2004; Boyd, 2007; 2006; 2004). Türkiye'de de Goffman'ın kavramlarını sosyal medyada benliğin sunumu yönü ile değerlendiren birçok güncel çalışmanın olduğunu söylemek mümkündür (Soydaş ve Tandaç Güneş, 2020; Akgün, 2018; Kavut, 2018; Ertürk, 2016). Ancak sembolik etkileşimci olan Goffman'ın yaklaşımının sosyal yapıların etkisini göz ardı etmesi nedeni ile yapılan çalışmalarda performanslar toplumsal yapılardan bağımsız bir şekilde ele alınmıştır. Bu çalışma, performansları Bourdieu'ya ait; alan, sermaye, habitus gibi kavramlar ile birlikte değerlendirerek performansların ardındaki toplumsal yapılara odaklanması yönüyle literatürdeki diğer çalışmalardan ayrılmaktadır.

Çalışmanın literatür kısmında ilk olarak kimlik, benlik, medya ve tüketim ilişkisi tartışılacak, ardından vücut geliştirme ve fitnessın popülerleşme süreçleri medyaya paralel bir şekilde ele alınacak ve sonrasında bedene odaklanan sosyolojik yaklaşımlara değinilecektir. Yöntem bölümünde araştırmanın nasıl tasarlandığı ele alınacak, bulgular ve tartışma kısmında ise kişisel antrenörlerin eylemleri Goffman ve Bourdieu'nun kavramlarıyla değerlendirilecek ve çalışma sonlandırılacaktır.

\section{KIMLIK, BENLiK, MEDYA VE TÜKETIM İLişKisi}

Günümüz dünyasında kültür ve etkileşim biçimleri 1960 'lı yıllar ve sonrası dönemde yaşanan birçok toplumsal ve teknolojik değişime bağlı olarak bambaşka bir hâl almıştır. iktisadi anlamda kapitalizmden ulusötesi kapitalizme, liberalizmden neoliberalizme, üretim teknolojilerinde fordizmden postfordizme geçilmesi, bilgisayar ve internet teknolojilerindeki gelişmeler bu dönüşümü oluşturan önemli kilometre taşlarından bazıları olarak değerlendirilebilir (Castells, 2008). Yaşananlara paralel olarak insan aklını dünyanın merkezine alan modern paradigma (Kant, 2020) ve onun ortaya çıkardığı rasyonel ve bütüncül mefhumlar işlerliğini yitirmeye başlamıs; makro yapılar ve büyük söylemler yerini daha mikro meselelere ve tikel olana bırakmıştır (Lyotard, 1997). Yeni paradigma, farklı düşünce ve noktalara odaklanan farklı isimler tarafından postmodernite, geç modernite, akışkan modernite, ağ toplumu gibi farklı biçimlerde tanımlanmaktadır. Yaklaşımların hepsinin ortak noktasında ise günümüz toplumsal düzeninin bir şekilde eskisinden farklı bir hâl alması; ekonominin üretim merkezli olmaktan tüketim merkezli olmaya kayması, buna bağlı olarak sınıf kavramının -tamamen olmasa da ciddi boyuttaparçalanarak kendini daha mikro düzeyde bir kimlik anlayışına teslim etmesi, bireyselleşmenin ileri boyutlara varması ve yapısal yaklaşımların bireyi anlamada yetersiz kalması, medyanın benlik ve kimlikler üzerinde belirleyici bir konuma gelmesi gibi durumlar sayılabilir.

Benlik en basit ve yalın şekilde kişinin kendini tanıma hali, kendi hakkındaki yargıların toplamı olarak tanımlanabilir (James ve Miller, 2007). Fakat bu yargıların başkaları ile kıyaslama sonucu oluşması nedeni ile bireysel olduğu kadar sosyal de bir kavramdır. Benzer şekilde Mead (1972) de ayna benlik yaklaşımında benliğin içten gelen davranışlar kadar başkalarının bu davranışa verdiği tepkiler ile de şekillendiğini savunmaktadır. Bir tercih ya da davrışı benimsemek aynı zamanda farklı tercih ve davranışları reddetmek anlamına geldiği için benlik kavramı kişisel kimlik, toplumsal kimlik ve öteki gibi kavramlar ile de iç içedir (Özdemir, 2010, s. 10). 


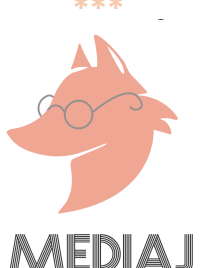

Latince idem kökünden türetilen aynılık, süreklilik anlamına gelen kimlik (identity) kavramı Türkçede ise zorunlu bir mensubiyeti, aynılı̆̆ı ve aidiyeti vurgulayan bir kavramdır (Dalbay, 2018, s. 162). Kimlik, modern öncesi süreçte çoğunlukla doğuştan gelen birkaç unsurla belirlenirken modern paradigmada bunlara siyasi görüş ve ekonomik sınıfa bağlı olarak sürdürülen yaşam tarzı gibi unsurlar eklenmiş ve kimlik görece dönüştürülebilir bir konuma evirilmiştir (Kellner, 2004, s. 187-188; Genç, 1991, s. 50). Modern sonrası süreçte ise ulus, sınıf gibi kolektif toplumsal yapılar esnemiş, parçalanmış, genişlemiş; bu durum da kimliğin kişisel tercihler aracılığı ile inşa edilen bir yapıya dönüştürerek benlik kavramının ön plana çıkması sonucunu doğurmuştur (Hall, 2000, s. 109-124). Ancak bu durum bireyi özgürleştirmemiş; aksine sınırsız alternatifler arasında kalan birey, kimliğini toplumsal alanda kabul ettirebilmek için benliğini sürekli olarak farklı göstergeler aracılığı ile yeniden ve yeniden sunmak zorunda kalmıştır (Bauman, 2014, s. 194; Giddens, 2012, s. 67). Bu sürecin kişiye özel üretimi mümkün kılan post-fordist üretim biçimin ortaya çıkışı ile aynı döneme denk gelmesi tesadüf değildir. Kişiye özel üretimi mümkün kılan teknolojiler ve bu ürünlerin pazarlamasına katkı sağlayan medya ve reklamcılık faaliyetleri kültürün gündelik yaşamın merkezine yerleşmesine büyük katkı sağlamıştır (Featherstone, 2010, s. 189).

Kimliklerin göstergeler aracılığı ile inşa edilmesi sürecinde medya çok kritik bir konumda bulunmaktadır. Bireyler kimliklerini sıklıkla kitle iletişim araçları aracılığı ile öğrendikleri yaşam tarzları ve ona ait göstergeler ile inşa etmektedir (Oskay, 2016, s. 29-33). McQuail, medyanın toplumsallaşma, kültürel devamlılık, kamuoyu yaratma, bilgilendirme ve eğlendirme işlevleri ile kimliklerin yeniden üretildiğini savunmaktadır (Mora, 2008, s. 6). Yine Frankurt ve Birmingham Okullarının çalışmaları bu süreci derinlemesine bir şekilde ele almaktadır. Yeni medya teknolojileri ise bu süreci, geleneksel kitle iletişim araçlarındaki tekten çoğa olan akışı, çoktan çoka çevirerek pasif konumdaki izleyicileri aktif içerik üretüketicilerine dönüştürmüştür (Manovich, 2001; Ritzer ve Jurgenson, 2010). Bu durum bireylerin geleneksel medyada pasif alımlayıcı olarak öğrendikleri yaşam tarzlarını yeni medya ile aktif bir şekilde sergileyebilmesi olarak da değerlendirilebilir. Böyle bir okuma, kullanıcıların hayatlarına dair yaptıkları paylaşımların narsistik bir değerlendirmeden ziyade sosyal olarak var olabilme zorunluğunu olarak okunabilmesini mümkün kılar (Bauman ve Lyon, 2013). Şu anın hızı içine hapsolan birey kimliğini yeniden inşa edebilmek için hiç durmadan koşturma, yeni göstergeler üretme ve tüketme durumunda kalmaktadır (Bauman, 2012, s. 236; Bauman, 2017; Featherstone, 2013). Baudrillard ise bir adım daha ileri giderek bu hızlı akışın içerisindeki gösterge bombardımanında bir şeyi anlamlandırmanın imkânsız hale geldiğine ve bu nedenle de göstergenin gerçekliğe dönüştüğünü ileri sürmektedir (Baudrillard, 2015, s. 14).

Bireylerin kimliklerini inşa ederken çeşitli göstergeler kullanmalarının/tüketmelerinin yanı sıra kendilerini de bedenleri aracılığı ile göstergeye dönüştürmektedir. Bedeni toplumsal anlamda ele alan önemli isimlerden biri Elias'tır. Elias'a göre toplumsal tarih aynı zamanda bedenin medenileşmesinin tarihidir; elle yemek yemek ya da geğirmek gibi fiziksel ihtiyaçları giderme biçimlerine dahi kurallar koyarak bedeni bürokrasi ile kontrol edilmesi gereken medenileştirilmiş bir nesneye dönüşmüştür (Yumul, 2000, s. 38). Foucault (2003) da Elias'a benzer şekilde bedeni söylemler ile oluşturulmuş toplumsal kontrolün, biyo-iktidarın kaynağı/nesnesi, ideolojilerin cisimleşmiş hali olarak görmektedir. Turner diğer isimlere benzer bir şekilde bedenin din, hukuk, tıp gibi toplumsal kurumların ürettiği bir nesne olarak görmekte ancak onlardan bir adım daha ileri giderek bu kurumların beden üzerine yansımalarını incelemek yerine bedeni inceleyerek bu 


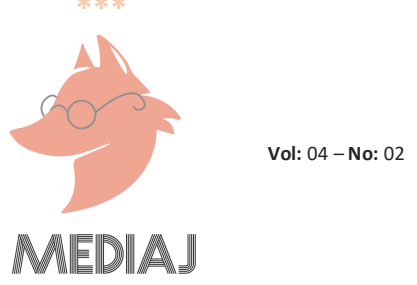

kurumlara dair çıkarımlarda bulunulabileceğini düşünmektedir (Turner, 1992, s. 29; Shilling, 2003, s. 78). Bu nedenle bedenselleşmiş toplum (somatic society) kavramını kullanan Turner, bedeni sosyal temsillerin cisimleşmiş hali olan dış beden ve bu bedeni ortaya çıkaran sosyal yapı ve düzenlemelerin iç yüzeyini kapsayan içsel beden ayrımıyla değerlendirmektedir (Çarpar, 2019 , s. 26). Turner'ı referans alan Featherstone ise tüketim toplumunun baskısıyla artık dış beden ve iç bedenin iç içe geçtiğini asıl amacın dış bedeni güzel tutmak olduğunu ileri sürerek beden göstergesi (body image) kavramını kullanmaktadır (Featherstone, 1982, s. 19). Shilling (1993) bu göstergenin (bedenin) temsilinin elzem bir konuma geldiğini ve güzel bedene erişme sürecinin bitmeyen bir projeye dönüştüğünü proje beden kavramı ile değerlendirmektedir. Wacquant (1995) ise bedensel sermaye kavramı ile neden insanların bedenlerini proje olarak ele aldığını açıklamaya çalışırken beden işi (body work) kavramıyla sermaye biriktirme sürecini irdelemektedir.

Tüm bunlardan yola çıkarak genel bir ifade ile kimliğin çeşitli göstergeler vasıtasıyla gerçekleştirilen benlik sunumları ile inşa edildiği, bedenin bu sürecin ayrılmaz bir parçası/tamamlayıcısı olduğu söylenebilir. Bu durumun en az gündelik yaşam kadar yeni medya üzerinde de görünür olduğu ve dolayısı ile bireylerin yeni medyadaki bedensel sunumlarının anlaşılmasının sosyal bilimlere büyük bir katkı sağlayacağı ileri sürülebilir.

\section{VÜCUT GELIŞTIRME VE FITNESS KÜLTÜRÜNÜN MEDYAYA PARALEL TARIHi}

Ağırlıklı olarak bedeni formda ve sağlıklı tutma, ona şekil verme aktivitelerine dayanan fitness, gündelik yaşamın baskın kültürel formlarından biri olarak karşımıza çıkmaktadır. Bedene odaklanan sporların tarihini antik dönemlere kadar götürmek mümkün olsa da günümüzdeki hali 1980'li yıllarda şekillenmeye başlamış, 2000'lerde ise güncel haline ulaşmıştır.

Vücut geliştirme kültürünün tarihi Antik Yunan'daki gymnasiumlar ile başladığı söylenebilir. Özgür erkekler burada bir yandan savaşa hazır olmak için vücutlarını günümüzdeki fitness egzersizlerine benzer hareketler ile geliştirmekte diğer yandan da ne kadar seçkin olduklarını diğer erkeklere gösterebilme şansı yakalardı (Kah ve Scholz, 2004, s. 14). Roma'da ise Antik Yunan'dan farklı olarak bedeni sağlıklı ve kaslı tutmak seçkinlere özel bir aktivite olmaktan ziyade ülkesini savaş durumunda karşı tarafa avantaj sağlayabilmeleri için bir gereklilik olarak görülmekte ve bu nedenle bedeni güçlü ve kaslı tutmak bir vatandaşlık görevi olarak düşünülmekteydi (Grant, 1964). Gladyatör savaşlarının popülerliği de bu düşüncenin bir yansıması olarak değerlendirilebilir (Harris, 1972). Osmanlı'da ise tüm spor aktiviteleri tekkelerin çatısı altında gerçekleşmekte ve ihtiyaçları vakıflar tarafından karşılanmaktaydı (Çumralıgil, 1999, s. 336). Bu tekkelerin kuruluş amacının da Antik Yunan ve Roma'ya benzer şekilde savaşa hazır konumda bulunmak olduğu söylenebilir (Gölbaşı, 2018, s. 44).

Vücut geliştirme kültürünün günümüzdeki pratiklerinin temelleri ise büyük ölçüde 19. Yüzyılın sonları ve 20. yüzyıla dayanmaktadır. Vücut geliştirme konusunda ön plana çıkan ilk isimler Eugene Sandow (1867 - 1925) ve Charles Atlas'tır (1892 - 1972). Ilk vücut geliştirmeci olan Sandow kendinden önce böyle bir pratik bulunmadığı için önce kas kütlesini arttırarak vücudunu şekillendirmiş ardından da beden eğitimi öğretmeni Profesör Atilla ile çalışmaya başlamıştır (Chapman, 1994, s. 10). Amerika ziyaretinde gördüğü büyük ilgi sonucunda Sandow'un kaslı 


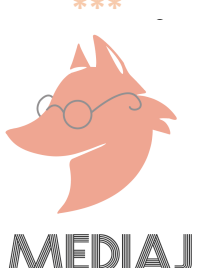

bedeninin kartpostallarda yer almaya başlamış, bu durum hem Sandow'u hem de kaslı beden imajını popüler hale getirmiştir. Bu durumdan faydalanan Sandow çeşitli vücut geliştirme egzersizleri yazmaya başlamış ve ilk vücut geliştirme yarışması olan Büyük Yarış'ı (Great Competition) düzenlemiştir (Andreasson ve Johansson, 2014, s. 96). Bu özellikleri nedeni ile Sandow, ilk vücut geliştirmeci, kişisel antrenör ve bugün çok popüler olan vücut geliştirme yarışmalarının kurucusu olarak değerlendirilebilir. Vücut gelişirmenin popüler hale geldiği süreç aynı zamanda sanayi devriminin sağlıksız sonuçlarının kendini gösterdiği, Büyük Buhran, dünya savaşları gibi krizler ile aynı döneme denk gelmektedir. Bu dönemde Genç Hıristiyan Erkekler Birliği (Young Men's Christian Association/YMCA) kurulmuş ve spor ve sporculuk anlayışını dönemin siyasi gerekliliklerine cevap verecek şekilde biçimlendirmiştir (Lynn, 2012, s. 547). Vücut geliştirme kültürünün ortaya çıkmasında bir diğer önemli figür olan Charles Atlas, işte tam da bu süreçte, kaslı bedeni güç ve erkeklik ile ilişkilendirerek güçlü bedeni güçlü bir ulusun ortaya çıkmasında gereklilik olarak tanımlamış ve ilk vücut geliştirme kitabı yazmış ve pazarlamıştır. (Andreasson ve Johansson, 2014, s. 96; Atlas'tan aktaran Reich, 2010, s. 457). Atlas bu yönüyle vücut geliştirmeyi medya aracılığı ile bir endüstriye dönüştüren ilk kişi olarak da değerlendirilebilir.

Vücut geliştirme Sandow, Atlas, YMCA gibi figürler ile temel hatları ile şekillense de 1960 'larda spor salonları hâlâ vücut geliştirmek için gerekli ekipmanlara sahip olmasına karşın sosyal olarak çekicilikten yoksun mekânlardı. Bu durumdan rahatsız olan eski vücut geliştirmeci, yatırımcı Joe Gold, 1965 yılında California Pasific Aveneu'da, ileride vücut geliştirme kültürünün ikonlarına dönüşecek Frank Zane, Arnold Schwarzenegger, Franco Columbu gibi antrenörlere ev sahipliği yapacak olan Gold Gym'i kurmuştur. Gold Gym'in başarısı vücut geliştirmenin bir yaşam tarzı olarak kabul görmesini kolaylaştırsa da, spor salonunun aşırı ticarileşmesinden rahatsız olan Joe Gold 1975 yılında Gold Gym'i satarak sektörden çekilmiş ve ticari potansiyelin farkında olan yeni sahipleri çeşitli dergilere, yarışmalara ve Pumpin Iron filmine sponsor olarak hızlı bir biçimde kurumsallaşmış ve küreselleşmiştir (Heffernan, 2015). Pumpin Iron filminin büyük başarısı, vücut geliştirme kültürünün karakteristik özelliklerini şekillendirerek onu bir alt kültür olmaktan çıkararak profesyonel atletlerin de kondisyonunu yükseltmek için kullandığı genel geçer bir alana dönüştürmüş ve Uluslararası Vücut Geliştirme Federasyonu (International Federation of Bodybuilding and Fitness) gibi uluslararası organizasyonların kurulmasına önayak olmuştur (Johansson ve ark., 2017, s. 5). Bu popülerite aynı zamanda diğer Hollywood filmlerinin de kaslı oyuncular tercih etmelerine neden olmuş ve böylece vücut geliştirme popüler kültür ve medya aracılığı ile gündelik yaşamın merkezine yerleşmiştir.

Ancak vücut geliştirmenin bu denli hızla popüler hale gelmesi kas kütlesini daha kolay ve hızlı geliştirmeyi sağlayan sağlığa oldukça zararlı Androjenik steroidlerin (AAS) ortaya çıkmasına neden olmuştur. Kimyasalların yanı sıra, birçok sporcu kas kütlesini geliştirmeyi saplantı haline getirerek hayatını bunun üzerine kurmaya başlamış, bu durum vücut geliştirme kültürünün adını kötüye çıkararak $80^{\prime}$ lerin sonunda giderek popüleritesini yitirmesi sonucunu doğurmuştur. Vücut geliştirmenin yeniden popüler olması ise 2000 'li yıllarda güçten ziyade sağlığı vurgulayan fitness adı ile kendini revize etmesiyle gerçekleşmiştir. Yeni isim, Oxford sözlüğüne göre fiziksel olarak sağlıklı ve güçlü olmak anlamına gelirken (Oxford Dictionary) TDK tarafından ise sağlıklı yaşam olarak tanımlanmaktadır (TDK, 2020). Monaghan'a (2001, s. 91-93) göre vücut geliştirmenin amacı vücudu daha kaslı hale getirmekken fitness sağlıklı ve fit görünmeye 


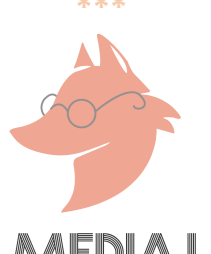

odaklanan rekreasyonel bir boş zaman aktivitesidir. Bu tanımlamalardan yola çıkarak fitnessın vücut geliştirmenin kötü yönlerinden soyutlanarak hatta bunları terse çevirerek tanımlandığı söylenebilir. Ek olarak sağılıkı kalma durumunun uzun vadeli bir süreç olması ile post-modern kimliklerinin sürekli kendini yeniden inşa etme gerekliliğinin arasında bir benzerlikten bahsetmek de mümkündür.

Vücut geliştirmenin Sandow'un kartpostalları ile görünür hale gelmesi, Atlas'ın yazdığı kitapla vücut geliştirme pratiklerinin şekillenmesi, Pumpin Iron filminin alanı ana akıma taşıması ve hedef kitlesini genişletmesi gibi durumlar göz önüne alınarak fitness ve medya arasında güçlü bir ilişki olduğu söylenebilir. Buradan yola çıkarak kitle iletişim araçlarının kaslı bedeni görünür hale getirerek ideal olarak sunduğundan bahsedilebilir (Yücel, 2019; Öztürk, 2012; Erdoğan, 2011; Baydur, 2010; Alexander, 2003; Cohan ve Hark, 1993). Yeni medya ise bireye içselleştirdiği bu ideali sunabilmesi için imkân yaratmaktadır.

Fitness alanının yeniden yükselişi, sosyal medya kültürünün gündelik yaşamın merkezine yerleşmesinin sonuçlarından biri olarak değerlendirilebilir. Bu perspektiften bakıldığında fitness kültürü; kimlik, medya, tüketim üçgeninin ortasında kritik bir noktada yer almaktadır. Bourdieu ve Goffman'ın yaklaşımlarının Barthes'ın göstergebilimi ile sentezlenmesi çalışmanın özgün yönünü oluşturmaktadır. Araştırma, fitness ile ilgilenen antrenörlerin Instagram'daki benlik sunumlarını inceleyerek günümüz kimlik ve benlik sunumu meselelerinin anlaşılmasına katkı sağlamayı amaçlamaktadır.

\section{YÖNTEM}

Araştırma nitel olarak tasarlanmış ve fenomenolojik olarak desenlenmiştir. Fenomenoloji, insanların içinde bulundukları ortamı nasıl anlamlandırdıklarını odaklanması yönü ile araştırmacıya bireysel eylemleri betimleyebilmek için avantaj sağlar (Merriam, 2009, s. 5). Çalışmada eylemler Goffman perspektifinden performans olarak ele alınmış ve performansların ardında yatan unsurlar Bourdieu'nun kavramları ile değerlendirilmiştir.

Araştırmada veri toplama aracı olarak doküman incelemesi kullanılmıştır. Doküman analizi, bir durumu basılı ya da elektronik kaynaklar, belgeler aracılığı ile inceleme ve değerlendirme amacı taşıyan sistematik bir yöntemdir (Kıral, 2020, s. 173). Toplanan veriler kendiliğinden doğal yolla oluşmuş ve belirli amaçlar ile bilinçli olarak oluşturulmuş olarak ikiye ayrılır. Doğal yolla oluşan veriler dışarıdan herhangi bir müdahaleye maruz kalmaması nedeni ile sonradan oluşturulan verilere göre çok daha güvenilirdir (Ulutaş, 2017, s. 286). Bu bağlamda sosyal medya içerikleri kendiliğinden oluşan veri olarak değerlendirilebilir.

Araştırmada Instagram üzerinde uzaktan eğitim etiketi ile paylaşım yapan ve biyografisinde uzaktan eğitim sunduğuna ya da kişisel antrenör olduğunu belirten bir ibare bulunan 8 kişisel antrenörün Instagram hesabı, amaca uygun rastgele örneklem ile seçilmiş ve ardından ölçüt örneklem kullanılarak her antrenörün önceden belirlenen profil biyografisi, antrenman, öncesisonrası, strateji, kişisel ve grup kategorilerindeki araştırmaya yardımcı olacağı düşünülen içerikleri toplanmıştır. Böylece, 59 fotoğraf ve bu fotoğrafların altında yer alan metinleri kapsayan araştırma verileri ortaya çıkmıştır. Amaca göre rastgele örneklem, araştırmacının 


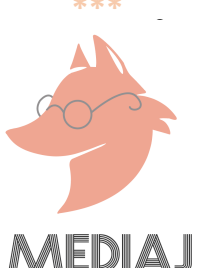

evrendeki çeşitlilik içerisinden araştırmanın amacını en iyi temsil ettiğini düşündüğü örnekleri seçmek istediği durumlarda kullanılmaktadır (Marshall ve Rossman, 2014). Bedensel sermayenin görünürlüğü nedeni ile sosyal medya platformları arasından etkileşimi görsel paylaşım aracılığı ile oluşturan Instagram seçilmiştir. Personal Trainer etiketi ile arama yapıldığında Türk antrenörlere ulaşmanın, kişisel antrenör etiketi ile arama yapıldığında ise fitnessa odaklanan antrenörlere ulaşmanın (etiketin ağılıkı olarak yaşam koçları tarafından kullanıldığı görülmüştür) zorluğu ile karşılaşılmıs ve fitness ile ilgilenen Türk kişisel antrenörlerin ağırlıklı olarak uzaktaneğitim etiketi altında kümelendikleri tespit edilmiştir. Benzer şekilde antrenörlerin sermayeleri aracılığı ile gerçekleştirdikleri performansları betimlemeye en çok yardımcı olacağı düşünülen kriterlere göre ölçütler (fotoğraf kategorileri) belirlenmiştir.

Veriler göstergebilim ve yorumlayıcı fenomenolojik analiz ile incelenmiştir. Göstergebilim özellikle iletişim alanında reklam, film, fotoğraf, sosyal medya içerikleri gibi görsel öğeleri incelemek için oldukça kullanışlı bir yöntemdir. Atabek ve Atabek'e (2007, s. 75) göre de göstergebilim, metinleri yapısal bir bütün olarak almakta ve görünen somut anlamın içinde gömülü olan özel anlama ulaşmayı amaçlamaktadır. Göstergedeki anlamı keşfetmeye odaklanan göstergebilim analiz yöntemlerinden ise Barthes'ın yaklaşımı kullanılmıştır. Fotoğrafların kendisine yer vermenin etik olmaması ve alan kısıtılığı bütün fotoğrafları betimlemeyi imkânsız hale getirmiştir. Bu nedenle antrenörlerin fotoğraflarında yer alan göstergeler okuyucuya tablolaştırılarak sunulmuştur (Tablo 1). Antrenörlerin alandaki performansına, sermaye birikimine avantaj sağlayacağı düşünülen göstergelerin başına Barthes perspektifinden yan anlam olarak değerlendirilebilecek (+) dezavantaj sağlayacağı düşünülen göstergelerin başına ise (-) işareti konmuştur. Barthes'ın yaklaşımı ve tablonun nasıl kurgulandığı Bulgular ve Tartışma bölümünün başında detaylı bir şekilde ele alınacaktır. Ardından ise antrenörlerin fotoğraf altı metinleri, güçlü ya da zayıf olduğu yönleri (sermayeleri) ile ilişkilendirilerek yorumlayıcı fenomenolojik analiz ile değerlendirilmiş, eylemlerinin/performanslarının ardında yatan eğilim ve amaçlar 'araştırmacının bakış açısı' ile betimlenmiş ve tartışılmıştır.

\section{BULGULAR VE TARTIŞMA}

\section{Göstergelerin Kültürel Yönü}

Çalışma kapsamında sekiz kişisel antrenörün profilinden toplanan 49 fotoğraf Barthes'ın göstergebilim yaklaşımı ile değerlendirilmiştir. Göstergebilimin kurucularından Barthes, Saussure'ün dilbilimi göstergebilimin alt başlığı olarak ele alma önerisini ters çevirerek göstergebilimi dilbilimin altına yerleştirmektedir (Ünal, 2017, s. 393-394). Sözcüğü anlamın kültürel olarak inşa edilmiş bir sembolü olarak gören Barthes (2003, s. 180), sözcük dışındaki diğer sembollerin de (fotoğraf, sinema, gösteri vb.) sözcüğe benzer şekilde konuştuğunu (mesajlar taşıdığını) ileri sürmektedir. Daha açık bir ifade ile anlamın göstergeler aracılığı ile yazarın ve okuyucunun bulundukları kültürel bağlam içerisinde şekillendiğini ifade etmektedir (Kearney, 2003, s. 321). Buradan yola çıkarak sosyal medya profilindeki bir fotoğrafın metin olarak iki farklı anlam taşıdığını ileri sürebiliriz; bunlardan ilki, fotoğrafı yükleyen kişinin oluşturmak istediği anlam, ikincisi ise fotoğrafı gören kişinin yaptığı çıkarımdır. Barthes, belirli bir kültürel bağlam içerisinde göstergenin doğrudan temsil ettiği nesneyi işaret etmesini düzanlam; bu temsilden çıkarılabilecek diğer anlamları ise yan anlam olarak tanımlamaktadır (Barthes, 
1993, s.70-72; Bircan, 2015, s. 19-20).

Yukarıdakilere ek olarak, fotoğrafın bir metin olarak değerlendirilmesinde fotoğraf altı yazılar da büyük önem arz etmektedir. Barthes (1977, s. 39-41) fotoğraf altı yazıların fotoğrafın taşıyabileceği sonsuz anlamlar arasından istenen anlama yönlendirme ve anlamı sabitleme gücüne sahip olduğunu ileri sürmekte ve bu durumu demirleme olarak tanımlamaktadır. Bu nedenle çalışmada incelenen fotoğraflar kategorize edilirken fotoğraf altı yazıları ile birlikte değerlendirilmiştir. Benzer şekilde yanamlamsal değerlendirme sürecinde de antrenörlerin yaptığı demirlemeler göz önünde bulundurulmuştur.

Çalışmada, kişisel antrenörlerin ${ }^{5}$ mahremiyetini koruyabilmek amacı ile fotoğraflara doğrudan yer verilmemiştir. Fotoğraf ve fotoğraf altı yazıları öncelikle düzanlamsal göstergeler olarak tablolaştırılmış, sonrasında ise Goffman ve Bourdieu'nun yaklaşımları bağlamında alanda yaratacağı potansiyel avantaj ve dezavantajlarına göre yan anlam olarak değerlendirilebilecek artı (+) ve eksi (-) ile işaretlenmiştir.

Tablo 1. Antrenörlerin Sermaye Göstergeleri

\begin{tabular}{|c|c|c|c|c|c|}
\hline & \multirow{2}{*}{$\begin{array}{l}\text { Ekonomik } \\
\text { Sermaye }\end{array}$} & \multicolumn{3}{|c|}{ Kültürel Sermaye } & \multirow{2}{*}{$\begin{array}{l}\text { Sosyal } \\
\text { Sermaye }\end{array}$} \\
\hline & & $\begin{array}{c}\text { Somutlaşmış Kültürel } \\
\text { Sermaye / Bedensel } \\
\text { Sermaye }\end{array}$ & Nesneleşmiş & Kurumsallaşmış & \\
\hline KA 1 & $\begin{array}{l}\text { + Çevrimiçi } \\
\text { antrenörlük } \\
\text { + Kendine ait } \\
\text { spor giyim } \\
\text { firması } \\
\text { +Sporcu } \\
\text { besinleri } \\
\text { satan } \\
\text { firmadan } \\
\text { sponsorluğu } \\
\text { + Sporcu Ek } \\
\text { besin } \\
\text { firmasından } \\
\text { sponsorluk } \\
\text { + dekore } \\
\text { edilmiş bir } \\
\text { evde } \\
\text { yaşaması } \\
\text { + gittiği spor } \\
\text { salonunun } \\
\text { yüksek } \\
\text { ekipman } \\
\text { kalitesi ve } \\
\text { kurumsallığı }\end{array}$ & $\begin{array}{l}\text { +Bilgilendirici } \\
\text { paylaşımlar } \\
\text { +Fotoğraflardaki teknik } \\
\text { kalite } \\
\text { +Profildeki görsellerin } \\
\text { birbirleri ile uyumu } \\
\text { + başarılı etiket } \\
\text { kullanımı } \\
\text { +Kaliteli Giyim } \\
\text { Çok kaslı beden }\end{array}$ & $\begin{array}{l}\text { + Kişisel web } \\
\text { sitesi } \\
\text { + Youtube } \\
\text { kanalı }\end{array}$ & $\begin{array}{l}\text { +Fitness } \\
\text { antrenörlük } \\
\text { sertifikası } \\
\text { + WBFF Pro } \\
\text { Fitnes Model } \\
\text { (dereceli) }\end{array}$ & $\begin{array}{c}480.000 \\
\text { Takipçi } \\
\text { +World } \\
\text { Beautiy } \\
\text { Fitness \& } \\
\text { Fashion } \\
\text { +Sporcu } \\
\text { besinleri } \\
\text { firması } \\
\text { (Sponsorluk) } \\
\text { + Sporcu ek } \\
\text { besin firması } \\
\text { (Sponsorluk) }\end{array}$ \\
\hline KA 2 & + Reel ve & +Kullanıcılara bilimsel & + Kişisel web & +Fitness & 98.400 \\
\hline
\end{tabular}

5 İncelenen antrönerler, kişisel antrenör kelimesinin baş harfleri alınarak KA şeklinde kısaltılmış ve numaralandırılmıştır. Tablo ve devamında antrenörlerden kodları ile bahsedilecektir. 
MEEDIAJ

\begin{tabular}{|c|c|c|c|c|c|}
\hline & $\begin{array}{l}\text { çevrimiçi } \\
\text { antrenörlük } \\
\text { yapması } \\
+ \text { +̧̇cinde } \\
\text { bulunduğu } \\
\text { setlerin ve } \\
\text { buradaki } \\
\text { dekoratif } \\
\text { unsurların } \\
\text { kalitesi (iş } \\
\text { yeri ve } \\
\text { yaşam alanı) } \\
+ \text { yaşadığı } \\
\text { semt } \\
+ \text { kullandığı } \\
\text { markaların } \\
\text { kalitesi }\end{array}$ & $\begin{array}{l}\text { bilgi sunması } \\
\text { + Fotoğraflardaki teknik } \\
\text { kalite } \\
\text { + Profildeki görsellerin } \\
\text { birbirleri ile uyumu } \\
\text { + Başarıı etiket } \\
\text { kullanımı } \\
\text { Çok kaslı beden }\end{array}$ & $\begin{array}{l}\text { sitesi } \\
+ \text { Youtube } \\
\text { kanalı } \\
\text { + Kişisel logo* } \\
\text { + Profilde } \\
\text { kurumsal } \\
\text { kimlik } \\
\text { kullanımı* }\end{array}$ & $\begin{array}{l}\text { antrenörlük } \\
\text { sertifikası } \\
\text { + Men's Fitness } \\
\text { Fit Model } \\
\text { Yarışması } \\
\text { (Dereceli) } \\
\text { + Gösterge } \\
\text { değeri yüksek } \\
\text { lise ve } \\
\text { üniversite } \\
\text { diploması }\end{array}$ & $\begin{array}{c}\text { +Takipçi } \\
\text { Men's } \\
\text { Fitness } \\
\text { (yarışma } \\
\text { aracılığı ile) }\end{array}$ \\
\hline KA 3 & $\begin{array}{l}\text { + Reel ve } \\
\text { çevrimiçi } \\
\text { antrenörlük } \\
\text { yapması } \\
\text { - Iç̧inde } \\
\text { bulunduğu } \\
\text { setlerin ve } \\
\text { buradaki } \\
\text { dekoratif } \\
\text { unsurların } \\
\text { kalitesi (iş̧ } \\
\text { yeri ve } \\
\text { yaşam alanı) } \\
\text { - Geçmişte su } \\
\text { dağıtım } \\
\text { firmasında } \\
\text { işçi olarak } \\
\text { çalışması }\end{array}$ & $\begin{array}{l}\text {-Yazım hataları } \\
\text {-Sürekli aynı etiketleri } \\
\text { kullanma } \\
\text {-tamamı büyük harfle } \\
\text { yazıımış fotoğraf altı } \\
\text { yazıları } \\
\text {-Profil biyografisinde } \\
\text { danışmanlı̆ıın ücretli } \\
\text { olduğunu belirtmesi } \\
\text { - Dikkat çekecek giyisiler } \\
\text { (uyarııı renker) } \\
\text { Aşırı kaslı beden }\end{array}$ & & $\begin{array}{l}\text { +Milli sporculuk } \\
\text { + Dördüncü } \\
\text { kademe baş } \\
\text { antrenörlük } \\
\text { belgesi } \\
\text { + Profesyonel } \\
\text { vücut geliştirme } \\
\text { dünya } \\
\text { şampiyonluğu } \\
\text { (Dereceli) } \\
\text { + Amatör Vücut } \\
\text { Geliştirme } \\
\text { Yarışması } \\
\text { Tükiye'de } 5 \text { kez, } \\
\text { Avrupa ve } \\
\text { Dünya'da } 1 \text { kez } \\
\text { (Dereceli) }\end{array}$ & $\begin{array}{l}74.600 \\
\text { Takipçi } \\
\text { +Türkiye } \\
\text { Vücut } \\
\text { Geliştirme } \\
\text { ve Fitness } \\
\text { Fedarasyonu } \\
\text { (Yarışma } \\
\text { aracılığı ile) }\end{array}$ \\
\hline KA 4 & $\begin{array}{l}\text { + Reel ve } \\
\text { çevrimiçi } \\
\text { antrenörlük } \\
\text { yapması } \\
+ \text { Iç̧inde } \\
\text { bulunduğu } \\
\text { setlerin ve } \\
\text { buradaki } \\
\text { dekoratif } \\
\text { unsurların } \\
\text { kalitesi (iş } \\
\text { yeri ve }\end{array}$ & $\begin{array}{l}\text { + Kullanıcılara bilimsel } \\
\text { bilgi sunması } \\
\text { + Fotoğraflardaki teknik } \\
\text { kalite } \\
\text { + Profildeki görsellerin } \\
\text { birbirleri ile uyumu } \\
\text { + Başarılı etiket } \\
\text { kullanımı } \\
\text { + Giyim tarzında sadelik } \\
\text { Atletik ve sıkı beden }\end{array}$ & $\begin{array}{l}\text { + Youtube } \\
\text { kanalı } \\
\text { + Takipçileri } \\
\text { için hazırladığı } \\
\text { sunumlar }\end{array}$ & $\begin{array}{l}\text { + Kişisel eğitim } \\
\text { satma (selling } \\
\text { personal } \\
\text { training) } \\
\text { sertifikası }\end{array}$ & $\begin{array}{c}12.300 \\
\text { Takipçi } \\
+ \text { Life Fitness } \\
\text { Türkiye } \\
\text { (eğitim } \\
\text { aracılığı ile) }\end{array}$ \\
\hline
\end{tabular}




\section{MEDIAJ}

\begin{tabular}{|c|c|c|c|c|c|}
\hline & $\begin{array}{l}\text { yaşam alanı) } \\
+ \text { yaşadığı } \\
\text { semt } \\
+ \text { kullandığı } \\
\text { markaların } \\
\text { kalitesi }\end{array}$ & & & & \\
\hline KA5 & $\begin{array}{l}\text { + Reel ve } \\
\text { çevrimiçi } \\
\text { antrenörlük } \\
\text { yapması } \\
\text { + Içinde } \\
\text { bulunduğu } \\
\text { setlerin ve } \\
\text { buradaki } \\
\text { dekoratif } \\
\text { unsurların } \\
\text { kalitesi (iş } \\
\text { yeri ve } \\
\text { yaşam alanı) }\end{array}$ & $\begin{array}{l}\text { + Kullanıcılara sporcu } \\
\text { yiyecek tarifleri sunması } \\
\text { + Profesyonel fotoğrafçı } \\
\text { tarafından çekilen } \\
\text { fotoğraflar } \\
\text { + Profesyonel video } \\
\text { çekimleri } \\
\text { + Kaliteli giyim } \\
\text { + Giyisiler arası uyum } \\
\text { - Paylaşımlarında etiket } \\
\text { kullanmama } \\
\text { Çok kaslı beden }\end{array}$ & $\begin{array}{l}\text { +Hazırladığı } \\
\text { özel sporcu } \\
\text { yiyecekleri }\end{array}$ & & $\begin{array}{l}31.800 \\
\text { Takipçi }\end{array}$ \\
\hline KA 6 & $\begin{array}{l}\text { + Reel ve } \\
\text { çevrimiçi } \\
\text { antrenörlük } \\
\text { yapması } \\
\text { +giyim } \\
\text { firması } \\
\text { sponsorluğu } \\
+ \text { Ek besin } \\
\text { takviyesi } \\
\text { sponsorluğu } \\
+ \text { İçinde } \\
\text { bulunduğu } \\
\text { setlerin ve } \\
\text { buradaki } \\
\text { dekoratif } \\
\text { unsurların } \\
\text { kalitesi (iş } \\
\text { yeri ve } \\
\text { yaşam alanı) }\end{array}$ & $\begin{array}{l}\text { - Sürekli aynı etiketleri } \\
\text { kullanması } \\
\text { - Gündelik hayatından } \\
\text { kişisel karelere dahi } \\
\text { sponsorları etiketlemesi } \\
\text { - Metinlerdeki yazım } \\
\text { hataları ve anlatım } \\
\text { bozuklukları } \\
\text { Çok kaslı beden }\end{array}$ & $\begin{array}{l}\text { + YouTube } \\
\text { kanalı }\end{array}$ & $\begin{array}{l}\text { + Fitness } \\
\text { antrenörlük } \\
\text { sertifikası } \\
\text { + WBFF Pro } \\
\text { Fitness Model } \\
\text { (dereceli) }\end{array}$ & $\begin{array}{c}23.400 \\
\text { Takipçi } \\
+ \text { WBFF Pro } \\
\text { Fitness } \\
\text { Model } \\
\text { (Yarışma } \\
\text { aracilığı ile) } \\
\text { + Sporcu ek } \\
\text { besin firması } \\
\text { (Sponsorluk) } \\
\text { + giyim } \\
\text { firması } \\
\text { (KA1'in } \\
\text { firması/ } \\
\text { sponsorluk } \\
\text { aracilığı ile) }\end{array}$ \\
\hline KA7 & $\begin{array}{l}\text { +Beden } \\
\text { eğitimi } \\
\text { öğretmeni } \\
\text { olması } \\
\text { +Çevrimiçi } \\
\text { antrenörlük } \\
\text { yapması } \\
+ \text { İçinde }\end{array}$ & $\begin{array}{l}\text { - İçerikle uyumsuz etiket } \\
\text { kullanımı } \\
\text { Aşırı kaslı beden }\end{array}$ & $\begin{array}{l}\text { + Fitness ile } \\
\text { ilgili e-kitap }\end{array}$ & $\begin{array}{l}\text { + Beden eğitimi } \\
\text { öğretmenliği } \\
\text { diploması } \\
\text { + Milli Sporcu } \\
\text { + Uluslararası } \\
\text { Fitness ve Vücut } \\
\text { Geliştirme } \\
\text { Yarı̧ması; }\end{array}$ & $\begin{array}{c}27.600 \\
\text { Takipçi } \\
\text { +Türkiye } \\
\text { Vücut } \\
\text { Geliştirme } \\
\text { ve Fitness } \\
\text { Fedarasyonu } \\
\text { (yarışma }\end{array}$ \\
\hline
\end{tabular}




\section{MEDIAJ}

\begin{tabular}{|c|c|c|c|c|}
\hline & $\begin{array}{l}\text { bulunduğu } \\
\text { setlerin ve } \\
\text { buradaki } \\
\text { dekoratif } \\
\text { unsurların } \\
\text { kalitesi (iş } \\
\text { yeri ve } \\
\text { yaşam alanı) }\end{array}$ & & $\begin{array}{l}\text { Türkiye'de } 2 \\
\text { kez, Dünyada } 1 \\
\text { kez (dereceli) } \\
\text { + Men's } \\
\text { Physique } \\
\text { Türkiye } \\
\text { Yarışması } 2 \text { kez } \\
\text { (Dereceli) }\end{array}$ & $\begin{array}{l}\text { aracılığı ile) } \\
\text { + Men's } \\
\text { Physique } \\
\text { (yarışma } \\
\text { aracılığı ile) }\end{array}$ \\
\hline KA8 & $\begin{array}{l}\text { + Reel ve } \\
\text { çevrimiçi } \\
\text { antrenörlük } \\
\text { yapması } \\
\text { + Protein } \\
\text { tozu satması } \\
\text { + Yaşam } \\
\text { alanındaki } \\
\text { dekoratif } \\
\text { unsurlar } \\
\text { - Çalıştığı } \\
\text { spor } \\
\text { salonununda } \\
\text { ki dekoratif } \\
\text { unsurlar }\end{array}$ & $\begin{array}{l}\text { + Başarılı etiket } \\
\text { kullanımı } \\
\text { - Dikkat çekecek giyisiler } \\
\text { (uyarıcı renker) } \\
\text { Aşırı kaslı beden }\end{array}$ & $\begin{array}{l}\text { + Milli sporculuk } \\
\text { + Çeşitli } \\
\text { yarışmalardan } \\
\text { dereceler (isim } \\
\text { verilmemiş) }\end{array}$ & $\begin{array}{c}56.100 \\
\text { Takipçi } \\
\text { +Türkiye } \\
\text { Vücut } \\
\text { Geliştirme } \\
\text { ve Fitness } \\
\text { Fedarasyonu } \\
\text { (Milli sporcu } \\
\text { olması } \\
\text { nedeni ile) }\end{array}$ \\
\hline
\end{tabular}

Goffman (2014, s. 234), benliği "sahnede belli bir karakteri canlandıran bireyin başkalarına vermeye çalıştığı (genellikle güvenilir) bir imaj" olarak tanımlar. Bu imajı yaratan eylem ise performanstır. Performans en basit hali ile "belli bir durumda belli bir katılımcının diğer katılımcılardan herhangi birini etkilemeye yönelik tüm etkileri" şeklinde tanımlanabilir (Goffman, 2014 , s. 28). Fotoğrafların da göstergeler aracılığı ile mesaj iletme özelliği düşünüldüğünde sosyal medyada paylaşılan fotoğraflar bir performans olarak değerlendirilebilir. Nitekim sosyal medya içeriklerini performans olarak değerlendiren birçok çalışma bulunmaktadır.

Etkileşimin gerçekleştiği, bir ölçüye kadar fiziksel olarak diğer alanlardan ayrılan alan ise sahne ya da performans bölgesini oluşturur (Goffman, 2014, s. 107). Sahnenin "önünde, içinde veya üzerinde sürekli sergilenen insan faaliyetlerine ortam ve sahne sunan mobilya, dekor, fiziksel tasarım ve diğer arka plan düzenlemelerini içeren set vardır" (Goffman, 2014, s. 33). Bu durum Instagram özeline uyarlandığında sosyal medya sahne, fotoğraflardaki arka plan ise set olarak değerlendirilebilir. Set ögeleri, anlam taşıyan bir gösterge olduğu düşünüldüğünde, performansı gerçekleştirene dair izlenimler sunduğu söylenebilir. Bourdieu’ya (2014, s. 362-363) göre zevkler sınıfsal birtakım izler taşır: alt sınıf sınırlı kaynağa sahip olduğu için daha işlevsel şeylere yaklaşırken orta sınıf kendini alt sınıftan ayırabilmek adına estetik kaygılara yönelir; üst sınıf ise tüm bunlardan azade bir şekilde onu taklit eden orta sınıftan kendini ayıracak şekilde beğenilerini konumlandırır. Bu bağlamda sadece teknik ekipmanlara işlevsel dekorasyona yönelen spor salonları, dar mekânlar, düşük kalite ürün ve bilinmeyen markalar, bu özellikleri barındıran yaşam alanları tabloda negatif; tam tersi göstergeler ise pozitif olarak konumlandırılmıştır. 


\section{MEDIAJ}

Performansa tekrar geri dönecek olursak Goffman'a göre (Goffman, 2014, s. 16-17) bireyin eylemde bulunması (oyuncu) durumu kaçınılmaz olarak gözlemcinin (izleyici) de çıkarımda bulunmasını doğuracaktır. Bunlardan oyuncunun maksatı ifadeleri verilen izlenimi, izleyicilerin bu kasıtlı eylemlerden yaptığı çıkarımlar ise yayılan izlenimi oluşturur (Goffman, 2014, s. 17-18). O halde verilen izlenim düz anlam, yayılan izlenim ise yan anlam olarak değerlendirilebilir. Oyuncuların izlenim vermek için yaptığı şey ise genelde belli rolleri oynamaktır. Rol "Bir performans sırasında gözler önüne serilen önceden belirlenmiş ve başka durumlarda da sergilenebilecek ya da oynanabilecek eylem kalıbını" ifade etmektedir (Goffman, 2014, s. 28). Araştırma bağlamında kişisel antrenör rolü oynayan profiller seçilmiştir.

\section{"4. Kademe BaşAntrenör" (KA3, profil biyografisi)}

"Temel güçlenme, kas gelişimi, sporcu beslenmesi. Birebir ders ve uzaktan koçluk için iletişime geçin" (KA4, profil biyografisi)

"Spor Bilimcisi / Personal trainer" (KA6, profil biyografisi)

"Physical Education Teacher" (KA7, profil biyografisi)

Instagram biyografisinde yer verilen ifadelerin profil sahibini tanıtan anahtar kavramlar olduğu düşünüldüğünde, kullanııların burada öne çıkmak istedikleri özelliklerini yazdıkları düşünülebilir. Bu bağlamda yukarıdaki metinlerin her biri kullanıcıların kişisel antrenör rolünü ön plana çıkarmak istediklerini gösterir niteliktedir.

Bireyler set içerisinde performanslarını sergileyip rollerini oynarlarken onları tamamlayan birtakım göstergeler eşlik eder. Goffman (2014, s. 33) bu göstergeleri kişisel vitrin olarak isimlendirir. Cinsiyet, yaş, etnik köken, beden tipi, jest, mimik, duruş şekli, kıyafetler, aksesuar ve dövmeler kişisel vitrin içerisinde değerlendirilebilir. Kişisel vitrin hususunda da set ve dekorasyondakine benzer sınıfsal ayrışmalar görülür; alt sınıf genellikle bir statü sahibi olmadığı için daha doğal ve içinden geldiği gibi yaşar, orta sınıfa doğru çıkıldıkça ise konum ve statüye uygun hareket etme kaygısı artar ve böylece ifadeler daha otokontrollü bir hal alır. Giyim konusunda da benzer bir durum kendini gösterir: alt sınıf insanlar daha az bütçe ayırmak zorunda kaldıkları için daha işlevsel ve ucuz ürünlere (kumaş, renk, kesim gibi özellikleri vasıtası ile betimlenebilecek) yönelirken orta sınıf bulunduğu toplumsal alana uygun ve estetik görünmesini sağlayacak ürünleri seçer; üst sınıfsa uygunluk ve estetik normları zaten içselleştirmiş olduğu için bunu orta sınıfa göre çok daha göstermeden ve hissettirmeden yapmayı başarır ve böylece kendini orta sınıftan da ayırmış olur (Bourdieu, 2014, s. 296-308). Bu bağlamda marka, kumaş dokusu, model, darlık gibi giyim ile ilgili unsurlar bedensel sermaye; yazım ve anlatım bozuklukları, kelime seçimi, üslup gibi unsurlar ise somutlaşmış kültürel sermaye başlığı altında kişisel antrenöre getirdiği avantaj-dezavantaj durumuna göre Tablo $1^{\prime}$ de konumlandırılmıştır.

\section{Bourdieu Bağlamında Kişisel Antrenörlerin Performansları}

Goffman'a (2014, s. 71) göre oyuncular performanslarında uygun unsur ve ifadeleri ön plana çıkarırken uygun olmayanları gizleme stratejisi ile ifadesel bütünlük sağlar. Araştırma 


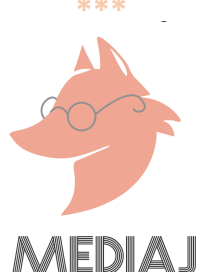

bağlamında incelenen kişisel antrenörlerin her biri farklı yollarla da olsa kişisel antrenörlük performansındaki başarısını öne çıkarmaya çabaladığı gözlemlenmiştir. Goffman, yaklaşımı ile kişilerin eylemlerini (araştırma bağlamında ise paylaşımlarını) okumaya izin verse de bunu yaparken kimin neden farklı yollara başvurduğunu açıklamakta yetersiz kalır. Bourdieu'nun yaklaşımı ise bu soruyu tatmin edici bir biçimde cevaplamaktadır.

Bourdieu toplumsal yaşamı oyun metaforu ile açıklamaktadır. Ona göre her birey sahip olduğu ekonomik, kültürel (bedende somutlaşan; resim, kitap gibi nesneleşen ve diploma gibi kurumsallaşan) ve sosyal sermayeyi kullanarak faydaya (illusio) ulaşabilmek için oyun oynar; bu oyun bir alan üzerinde gerçekleşir ve her alanın kendine özgü kuralları (doxa) ve alanda daha büyük avantaj getirecek hâkim bir sermaye tipi vardır. Benzer alanlarda, benzer kurallara uyarak benzer miktarda sermaye ile oynamak benzer düşünce ve anlamlandırma kalıplarına sahip sınıfları, yani habitusu doğurmakta ve böylece bireysel eylem, toplumsal yapıları oluşturmaktadır. Ancak diğer yandan da bireysel eylemler de paradoksal bir biçimde içinde bulunulan toplumsal yapılar ile şekillenmektedir. Böyle bir yaklaşım ile hem birey toplumsal yapının içine hapsolmaz hem de toplumsal yapıların etkileri göz ardı edilmemiş olur (Bourdieu, 1986; Bourdieu ve Wacquant, 2003). Bouridieu bedeni, kültürel sermayenin alt başlığı olan somutlaşmış kültürel sermaye içerisinde değerlendirirken öğrencisi Wacquant (1995) bedensel sermaye kavramını kullanır.

Wacquant, bedensel sermayenin geliştirmeye yönelik tüm eylemleri beden işi (body work) kavramı ile tanımlar ve üç boyutta inceler: fiziksel boyut, bedeni istenen şekle sokmak için gerekli olan egzersizleri; zihinsel boyut beslenme, diyet, uyku saati gibi unsurları bedenine göre şekillendirmesini; sosyal boyut ise diğer iki boyutun sonucu olarak ortaya çıkan beden için her şeyi bırakma, disiplin, kendini adama ve çeşitli takıntıları kapsar (Wacquant, 1995, s. 76; Pedersen ve Tjørnhøj-Thomsen, 2017, s. 432).

“(...) Bu 7.5 sene içerisinde çok zorlandığım dönemler, psikolojik olarak kendimi iyi hissetmediğim anlar, gerçek anlamda sıkıldığım günler oldu ama hiçbir zaman pes etmedim ve geri adım atmadım. Bu yüzden şu an sizlerle bu fotoğrafları paylaşıp, bu yazıyı yazabiliyorum. (...)" (KA2 Öncesi sonrası fotoğrafı alt yazısı)

“(...) Hayat Sizin, Seçim Sizin. Hangi Resim Gibi Olmak Isterdiniz? Kendine Bakmayıp, Sağliksiz Bir Şekilde Yaşayip, Sağliksiz Bir Görünüme Sahip Olanmi ? Kendine Bakip, Sağlikli Bir Şekilde Yaşayip, Sağlikli Bir Görünüme Sahip Olanmi ? (...)" (KA6 Öncesi sonrası fotoğrafı altı yazısı)

"Hadi bi cesaret sende taşın altına koy eliiniiiii! Demiş şarkıda.. (...) Hiçbir şey imkansız değildir. Sadece emek, özveri, zaman ve sabır ister. (...)" (KA7 Öncesi sonrası fotoğraf altı yazısı)

Incelenen profillerin her birinin sahibi fitness alanındaki beden çalışması kavramına uygun düşecek doxaları yerine getirerek antrenör rolünü oynuyor olsa da, farklı habitus ve öznel deneyimlere sahip olması nedeni ile farklı stratejiler izlemektedir. Öyleyse, performansların habitus ve sermayeler ile birlikte değerlendirilmesi gerektiği söylenebilir.

Kültürel sermaye en basit biçimde "kişinin elde ettiği bilgi, yetenek, beğeni, eğitim biçimleri ve bunların sağladığı avantajlar" şeklinde tanımlanabilir (Misci Kip, 2010, s. 28). Kendi içerisinde 


\section{MEDIAJ}

konuşma tarzı, kelime seçimi, üslup, giyim, beden şekli gibi unsurlarla (Goffman'daki kişisel vitrine eş) bireyin bedeninde somutlaşan kültürel sermaye, bilgiler dahilinde ortaya çıkardığı kitap, makine, resim gibi nesneler aracılığı ile göstergeye dönüşen nesneleşmiş kültürel sermaye; içinde bulundukları kurumlardan öğrendiklerini somutlaştıran diploma, sertifika gibi unsurları kapsayan kurumsallaşmış kültürel sermaye gibi farklı alt başlıklara sahiptir (Bourdieu, 1984'ten Aktaran Featherstone, 2013, s. 174).

Antrenörlerin her biri yetkin bir izlenim verebilmek için nesneleşmiş kültürel sermayesini kullanmaktadır. İncelenen sekiz antrenörden altısının profilinde nesneleşmiş kültürel sermaye ile ilgili göstergeler (bkz Tablo 1) sunduğu görülmüştür. Ancak beklenin aksine nesneleşmiş kültürel sermaye ile takipçi sayısı arasında bir ilişki göze çarpmamıştır. Fakat nesneleşmiş kültürel sermayesi düşük iki antrenörün diğer altı antrenörden farklı olarak kurumsallıktan uzak göstergelere sahip spor salonunda çalıştığı görülmüştür. Öyleyse kültürel sermayenin kurumsal spor salonlarında çalışabilme konusunda çeşitli avantajlar ya da dezavantajlar yaratabileceği öne sürülebilir. Ayrıca nesneleşmiş kültürel sermaye ve somutlaşmış kültürel sermayenin birbirini tamamlar nitelikte olması dikkat çekicidir. Yine aynı iki antrenör, diğerlerine göre üslup olarak çok daha keskin ve agresiftir:

"Rüyalarınızdan vazgeçmeyin uyumaya devam edin (gülen emeoji)" (KA3 Grup fotoğrafı altı yazısı)

"Kimse bana işim ağır bu sporu yapamıyorum demesin... (...)" (KA3 Öncesi sonrası fotoğraf altı yazısı)

"Ter dökmeden hiç bir şey olmaz aga (yukarı işaret eden parmak emojisi)" (KA8 Antreman fotoğraf altı yazısı)

Bourdieu’ya göre habitus ağırlıklı olarak çocukluk ve ilk gençlik dönemlerinde bilinçsiz bir şekilde içselleştirilen ve süreklilik arz eden 'üretken eğilimler şeması' dır (Meder ve Çeğin, 2011, s. 248). Yani antrenörler her ne kadar benzer alanlarda çalışsalar, üç aşağı beş yukarı benzer bir gelirlere ya da bedensel sermayeye sahip olsalar da çocukluk ve gençlik deneyimleri, fitnessı farklı anlamlandırmaları sonucunu doğurmuştur.

"Neredeyse hiçbir zaman farklı sınıfların aynı pratikten aynı şeyi bekleyeceklerini varsaymamız için bir sebep yoktu: (...) halk sınıflarında jimnastikten beklenen güçlü bir beden biçimi ve onun gücünün gözle görünen dışavurumları veya sağlam bir bedenken, burjuvalar örneğinde bu beklenti sağıklı bir bedendir" (Bourdieu, 2014: 308).

Somutlaşmış kültürel sermaye ve onun uzantısı olan bedensel sermaye göstergeleri bu durumu dramatik bir biçimde göz önüne sermektedir. Aşırı kaslı ve geniş bir bedene sahip KA3'ün öncesi sonrası fotoğrafında su firmasında iş̧̧i olarak çalıştığı günlerden bir fotoğraf yer almakta ve üzerindeki gömlek ve kapri model, kesim ve renk ile alt sınıf habitusa dair izlenim yaymaktadır. Yine benzer bir durum KA8'in öncesi sonrası fotoğrafında da görülmektedir: KA8'in pazularını şişirdiği fotoğrafta boynuna zincir takması, pantolonunun rengi ve arka plandaki gecekondular alt sınıf habitusa dair izlenim yaymaktadır. Bu durumun tam tersi, incelenen antrenörler arasında atletik olarak tanımlanabilecek ince bir bedene sahip tek kişi KA4'te görülmektedir. İstanbul'un iyi semtlerinden birinde yaşayan, kaliteli (markalar) tercih eden ve sade giyinen, yüksek 


\section{MEDIAJ}

nesneleşmiş ve somutlaşmış kültürel sermayeye sahip ve kurumsal bir spor salonunda çalışan KA4, disiplinin önemini ve amacını çok daha farklı şekilde vurgulamaktadır:

“(...) Savaştığınız, daha iyisini, daha sağlıklısını yapmaya çalıştığınız tek şey 'dünkü haliniz' olsun. (...)" (KA4 Antreman fotoğraf altı yazısı)

Benzer şekilde kültürel sermayesi yüksek olan KA5 fitness yaşam tarzına bakış açısını şöyle ifade etmektedir:

"Sağlıklı\&Fit Bir Yaşam Tarzı Sıkıcı Olmak Zorunda Değildir (yeşil elma emojisi) (...)" (KA5 profil biyografisi)

Kişisel antrenörlerin performanslarına katkı sağlayan bir diğer sermaye tipi ise sosyal sermayedir. Sosyal sermaye, "az ya da çok az kurumsallaşmış karşılıklı tanıma ve tanıma ilişkisine sahip dayanıklı bir ağa sahip olmakla veya başka bir deyişle bir gruba üye olmakla bağlantılı olan gerçek veya potansiyel kaynakların toplamıdır" (Bourdieu, 1986, s. 51). Bu bağlamda kişisel antrenörlerin çalıştıkları spor salonları, katıldıkları yarışmalar, buralarda tanıştıkları insanlar, sponsorları, sosyal sermaye bağlamında değerlendirilebilir. Bu noktada dikkat çekici unsur, bedenin kas kütlesi ve güçlülük gibi kriterlere göre değerlendirildiği vücut geliştirme yarışmalarına katılan antrenörler ile sağlıklı ve fit görünüm gibi kriterlere göre değerlendirme yapan modellik yarışmalarına katılan antrenörlerin beden çalışması bağlamındaki düşüncelerindeki farklııktır. İki grup da disiplinin önemini vurgulayıp tüm rutinlerini spora göre planlarken ilk grup bunu çok daha erkeklik ile ilişkilendirerek yapmakta, ikinci grup ise daha çok öz disiplin, sağlıklı yaşam ve sosyalleşmeye göndermede bulunan ifadeler kullanmaktadır. Fitness odaklı yarışmalara katılan KA1 ve hem fitness hem de vücut geliştirme yarışmalarına katılan KA7'nin, antrenman yaptıkları arkadaşları ile birlikte çekildiği fotoğrafların altına yazdıkları metinler bu ayrımı çarpıcı bir şekilde göstermektedir:

"Akşamında 3 kg palamut yiyip yayıldığımız bir günün sabahı, karınlar aç, tipler kaymış (...)" (KA7 Grup fotoğraf altı yazısı)

“5 kişi idman hiç bu kadar güzel olmamıştı. @x hocamız hepimizi bitirdi :) Bende güzel ışık bulunca hemen yerimi aldım (gülümseyen emoji) herkese tekrar teşekkürler bu harika idman için (...)" (KA1 Grup fotoğrafı fotoğraf altı yazısı)

Sosyal sermaye ile ilgili bir diğer dikkat çekici durum ise sponsorluk ağı geliştirebilen antrenörlerin hepsinin modellik yarışmalarına katılıyor olmasıdır. Hatta KA6'nın sponsorluk aldığı giyim firması onunla aynı yarışmadan derece alan KA1'e ait firmadır. O halde genel bir özetle antrenörlerin habitusları bağlamında geliştirdikleri sosyal sermayenin fitness ve vücut geliştirme alanına dair algıları pekiştirdiği söylenebilir.

Bourdieu'ya göre diğer sermaye tiplerine kıyasla daha kritik bir konumda olan sermaye tipi ekonomik sermayedir. Bourdieu'ya (2010, s. 49) göre ekonomik sermaye; doğrudan paraya çevrilebilen mülkiyet haklarının kurumsallaşmış halidir. Ancak diğer sermaye tiplerinde belirleyici olmasına rağmen ekonomik sermaye Marxist söylemdeki gibi iktisadi alan ile sınırlı 


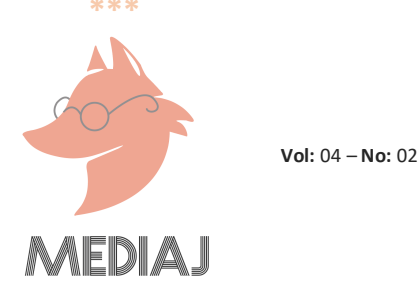

kalmaz; sürekli diğer sermayeler ile etkileşim halindedir (Göker, 2014, s. 282). Bu neden ile ekonomik sermaye sadece sahip olma ile sınırlandırılmamalı, bireylerin erişebildikleri ya da erişmeyi tercih ettiklerinin de ekonomik sermaye içinde değerlendirilmelidir. Nitekim çalışma uzaktan eğitim veren kişisel antrenörleri seçtiği için incelenen performansların bedensel sermayeyi ekonomik sermayeye dönüştürme amacı taşıdığı söylenebilir. Antrenörlerin Instagram profillerindeki temel amacın bedensel sermayeyi ekonomik sermayeye dönüştürmek olması nedeniyle ekonomik sermaye ile bedensel sermaye ve onun ayrılmaz bir parçası olan somutlaşmış kültürel sermaye birlikte ele alınacaktır.

Somutlaşan kültürel sermaye en basit hali ile kişinin bedeni, duruşu, konuşma tarzı, üslubu gibi bireyin bedeninde somutlaşan unsurları kapsar (Bourdieu, 1986, s. 244-245). Bu hali ile Goffman'ın kişisel vitrin kavramına denk gelmektedir. Ancak çalışma sosyal medyayı sahne olarak aldığı için bireylerin dijital alandaki performanslarını değerlendirmektedir. Bu nedenle gerçekte birbirine bağlı olan somutlaşmış kültürel sermaye göstergeleri ile beden birbirinden ayrılır. Ancak konuşma tarzı, ses tonu, kelime seçimi gibi kişinin kültürel sermayesi ile ilgili göstergelere dijital ortamda da ulaşmak mümkündür; yazım hataları, noktalama kullanımı, anlatım bozuklukları, kelime seçimi gibi unsurlar bu bağlamda değerlendirilebilir. Buna ek olarak, nasıl ki bir marka değeri onu taşıyan kişinin ekonomik sermayesine dair göndermede bulunuyorsa, dijital alanda fotoğrafın teknik kalitesinin de benzer göndermeler yaptığı savunulabilir.

Öncelikle Instagram 'alanında' kişisel antrenörlük performansı ile bedensel sermayeyi ekonomik sermayeye çevirebilmek için görünür derecede kaslı bir bedene sahip olmanın bir doxa olduğundan söylenebilir. Her ne kadar takipçi sayısına satın alınmış olabilme ihtimali nedeniyle çalışmada büyük önem atfedilmese de, KA1 dışındaki antrenörlerin takipçi sayıları arasında mantıklı bir tutarlılık mevcuttur. KA1'in ondan sonra gelen kişiden beş kat fazla takipçiye sahip olduğu düşüldüğünde, takipçi satın almış olması muhtemeldir. En az takipçiye sahip olan KA4 ise 12.000 takipçisi olmasının yanı sıra, bedeni atletik ve sıkı olarak tanımlanabilecek tek antrenördür. Ters orantılı olarak en geniş ve kaslı bedene sahip, fitnesstan ziyade vücut geliştirme ile ilgilenen KA3 ve KA7 ise takipçileri ile alana dair bilgi paylaşmamalarına rağmen takipçi sayısı en yüksek olan antrenörler arasındadır. Kişisel antrenörler ile yaptığı araştırma sonucunda görünüm ile yetkinlik izlenimi arasında çok güçlü bir ilişki olduğu sonucuna ulaşan Hutson'ın (2013) görüşmecilerinden biri durumu çarpıcı şekilde özetlemektedir: "Bedenin senin kartvizitindir."

Buna rağmen kaslı bir bedene sahip olmak, bedensel sermayeyi ekonomik sermayeye çevirebilmek için tek başına yeterli değildir. Antrenörlerin hepsi bedenlerini bir yandan gösterge olarak sunarken diğer yandan potansiyel müşterilerine kas kütlesini arttırma konusunda yardımcı olabileceklerine dair imada bulunan çeşitli stratejiler izlemektedir. Bu stratejiler arasında en sık başvurulansa kültürel sermayelerine dair göstergeler paylaşmaktır:

\footnotetext{
“Her insanın metabolizması, vücut tipi ve günlük rutini farklıdır. Bu yüzden kişiye özel planlama yapılıp o kişiye uygun bir beslenme ve antrenman programı hazırlanması gerekir. Takip ettiğiniz kişilerin yediği yemekler ve yaptığı antrenmanlar ile doğru sonuca varamayacağınız gibi, çeşitli sağlık sorunlarınada yol açabilirsiniz (...) Bu yüzden kişiye özel eğitimi sizlere sunuyorum (...)" (KA1 Strateji fotoğrafı altı yazısı)
} 


\section{MEDIAJ}

"Iyi bir eğitmen bulmak görünüş dışında nelere bağlıdır? (...) konu için sola kaydırın, kaynaklar ve ilgili kitaplar sunum sonunda gösterilmiştir. (...)" (KA4 strateji fotoğrafı altı yazısı)

"Merak ettiğin soruları yorum atarak sor (alev emojisi) cevaplayalım bilgiler kalıcı olsun (gözlüklü emoji) (...)" (KA5 Antrenman fotoğrafı altı yazısı)

Profilinde kültürel sermaye sunabilen antrenörlerin hepsi bu alanda yetkinliğini gösterebilmek için çeşitli performanslara girişmektedir. Ancak youtube kanalı, web sitesi olmayan ve kullanııılarıyla bilgi paylaşımayan kültürel sermayesi düşük antrenörler ise farklı stratejiler izlemektedir:

“Dikkatli bakın bu dört yıldızı bir tek futbol formalarında görürsünüz (güneş gözlüklü emoji) (Profesyonel olarak verdiğim Uzaktan Eğitim ile hızlı ve dengeli kilo verme kilo alma vücut geliştirme ve ev programları için whatsapp (telefon numarası)(...)" (KA3 Strateji fotoğraf altı yazısı)

"3aylik değişimdir..." (KA3 Strateji 2 fotoğraf altı yazısı)

“(...) Hem muhtesem bir degisime sahip olmayi, hemde para kazmayi Istiyorsaniz bu yarismayi sakin kacirmayin. 50 TL katılım ücreti olan bu yarışmada hem 1000 TL kazanabilir hem de para kazanma heyecanıyla motivenizi yüksek tutarak hayalinizdeki vucuda sahip olabilirsiniz.(...)" (KA6 Strateji fotoğraf altı yazısı)

“\%(gül emojisi) orijinal ürünler için ulaşın (mesaj emojisi)” (KA8 Öncesi sonrası fotoğraf altı yazısı)

KA3'ün strateji fotoğrafında 4. kademe başantrenörlük belgesinin fotoğrafı, strateji 2 fotoğrafı ise öğrencisinin öncesi ve sonrası fotoğrafı yer almaktadır. Fitness ve vücut geliştirme alanında yüksek derecede kurumsallaşmış kültürel sermayesine rağmen gündelik alandaki kültürel sermaye düşüklüğünün bildiklerini aktarma hususunda engel teşkil ettiği söylenebilir. Uzmanlığını herhangi bir açıklama yapmadan öğrencisinin bedeni ve antrenörlük belgesi aracılığı ile sunması bu durumu destekler niteliktedir. KA6 da benzer şekilde bilgi sahibi bir izlenim veremediği için pazarlama stratejileri ile uzaktan eğitim verme stratejisine yönelmiştir. KA8 ise sporcu ek besinleri satmaktadır. Bu satış metnini öncesi sonrası fotoğrafının altına kullanması KA3'e benzer şekilde ürünlerin faydalı olacağını kendi bedenindeki değişim ile göstermeye çalıştığına dair izlenim vermektedir.

Tüm bunlardan özetle, bedensel sermayeyi ekonomik sermayeye dönüştürmek için kaslı bir bedene sahip olmanın yeterli olduğundan bahsedilebilir. Nitekim, KA3, KA6 ve KA8'in izlediği stratejiler bunu gösterir niteliktedir. Ancak bu duruma karşın kültürel sermayenin, bedensel sermayeyi ekonomik sermayeye dönüştürme hususunda ciddi anlamda bir hareket alanı açtığını, daha uzman ve güvenilir bir imaj yaratmaya yardımcı olduğunu söylemek mümkündür.

Simgesel sermaye, diğer bütün sermaye tiplerinin anlam ya da tanınırlık kazanması yoluyla ortaya çıkan bir sermayedir (Bourdieu 2000, s. 242). Diğer bir deyişle, simgesel sermaye diğer sermaye tipleri gibi görünürlüğü olan bir sermaye türü değildir; kişinin ekonomik, sosyal, kültürel 


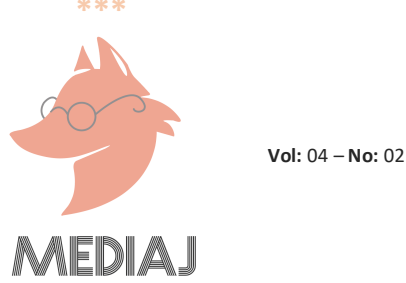

ve onun altındaki bedensel sermayesinin kişi üzerindeki yansımasıdır (Pedersen ve TjørnhøjThomsen, 2017, s. 432). Bu nedenle simgesel sermaye, bir nevi kişinin habitusunun izin verdiği ölçüde oluşan bilişsel kapasite ya da kişinin habitusunun sembolik yansıması olarak da değerlendirilebilir (Bourdieu, 1986, s. 52). Bu bağlamda, antrenörlerin seyirciye verdiği genel imaj simgesel sermaye olarak değerlendirilebilir. Araştırmacı deneyimim kapsamında kültürel sermayesi yüksek, takipçilerini vücut geliştirme konusunda bilgilendiren, bu konuda çeşitli kanallar aracılığı ile içerik üreten, yazım ve anlatım yeterliliği yüksek, kurumsal spor salonlarında çalışan antrenörlerin sembolik sermayesinin daha yüksek olduğu söylenebilir. Ancak simgesel sermaye habitus bağlamında algılandığı için bu bakış açısı orta sınıf habitusun izlerini yansıtmaktadır. Nitekim, yukarıdaki özellikleri taşımayan antrenörler de diğerleriyle benzer takipçiye ve etkileşime sahiptir. Bu durum göstermektedir ki, çok kaslı beden, maskulen ve sert ifadeler de simgesel bir değer yaratabilmektedir. Dijital sahnenin/alanın genişliği her habitustan antrenörün kendi habitusundan takipçi/öğrenci bulmasını mümkün kıldığını göstermektedir.

\section{SONUÇ}

Çalışma temel olarak kişisel antrenörlerin Instagram'da izledikleri stratejileri Wacquant'ın bedensel sermaye ve Bourdieu'nun sosyolojik yaklaşımıyla betimlemeyi amaçlamaktadır. Bu bağlamda fotoğraflardaki kişiler, mekânlar, çeşitli arka planlar Goffman'ın dramaturjik yaklaşımındaki terimler ile kategorize edilmiş ve her paylaşım, antrenör rolü oynayan bireyin belli bir izlenim verme maksadıyla sergilediği bir performans olarak görülmüştür.

Araştırmanın bulguları göstermektedir ki, kaslı bedene sahip olmak, Instagram alanında popüler bir antrenör olabilmek için doxa konumundadır. Nitekim incelenen sekiz kişisel antrenörden yedisi ortalama ve ortalama üzeri kas kütlesine sahiptir ve izleyicilere fayda sunmayan (vücut geliştirme konusunda çeşitli fikir ve ipuçları aktarmayan) antrenörlerin de takipçi sayısı ve etkileşim düzeyi en az diğerleri kadar yüksektir.

Antrenörler Instagram'da Wacquant'ın beden işi (body work) kavramının fiziksel, zihinsel, sosyal boyutları içerisinde değerlendirilebilecek söylemlere sıklıkla yer vermektedir. Egzersiz önerileri ve taktikleri fiziksel boyuta; yemek, ek besin, günlük rutinler ile ilgili öneriler zihinsel boyuta; mücadele, disiplin, istikrar gibi kavramlara yaptıkları vurgu ise sosyal boyut içerisinde değerlendirilebilir. Ancak özellikle sosyal boyut habituslara göre farklılık göstermektedir; paylaşımlarında alt sınıf habitusa ait göstergeler (gecekondu, boyuna zincir takma, işçi olarak çalışma vb.) bulunan antrenörler disiplin ve istikrarı bir savaş verme, galip olma ya da mağlup düşme gibi betimlerken orta sınıf habitusa ait göstergeler (sade giyim tarzı, bilindik markalar, üniversite eğitimi almış olma vb.) taşıyan antrenörler ise keyifli bir aktivite, hayallere kavuşmak için gösterilen çaba şeklinde betimlemektedir.

Antrenörler uzman ve güvenilir bir izlenim vererek bedensel sermayelerini ekonomik sermayeye çevirmek için sıklıkla kültürel sermayelerine başvurmaktadır. Sekiz antrenörden altısı kişisel web sitesi, youtube kanalı, sunum, e-kitap gibi araçlar ile takipçileriyle vücut geliştirme ve fitness ile ilgili egzersiz ve beslenme önerileri paylaşmaktadır. Ancak paylaşımda bulunmayan antrenörlerin de fitness alanında kültürel sermayeye sahip olduğunu gösteren göstergeler (antrenörlük sertifikaları, milli sporcu olma vb.) mevcuttur. Buradan yola çıkarak, Instagram'da 


\section{MEDIIAJ}

ya da yeni medya kanallarında antrenörlügün fitness alanına ek olarak anlatım, aktarma ve dijital okuryazarlık gibi farklı alanlara ait kültürel sermaye biçimlerini gerektirdiği söylenebilir. Ancak bedensel sermayesini ekonomik sermayeye çevirirken kültürel sermaye bariyerine takılan antrenörlerin de farklı stratejilere başvurdukları söylenebilir: fitness ile ilgili aldıkları eğitimi, katıldıkları yarışma ve dereceleri vurgulama, ek besin satışı gibi eylemler bunlara örnek verilebilir.

Vücut geliştirme yarışmaları bedenin gücüne, genişliğine ve kas miktarına odaklanırken modellik yarışmaları daha çok estetik beden, sağlıklı yaşam gibi unsurlara odaklanmaktadır. Kültürel sermaye ile antrenörlerin katıldıkları yarışma türü arasında bir ilişki olduğu yorumunda bulunulabilir; kültürel sermaye göstergeleri daha fazla olan antrenörlerin daha çok modellik yarışmalarını tercih ettiği ve üslup ve ifadelerinin vücut geliştirme yarışmalarına katılanlara oranla çok daha yumuşak olduğu söylenebilir. Aynı zamanda çeşitli sponsorluklar almış antrenörlerin hepsi modellik yarışmalarına katılmaktadır. Buradan yola çıkarak, modellik yarışmalarına katılanların bedensel sermayelerini ekonomik sermayeye daha rahat dönüştürdüğü söylenebilir.

Bireyin sahip olduğu tüm sermayelerin yarattığı izlenim olarak değerlendirilebilecek simgesel sermaye açısından değerlendirildiğinde ise eşitlikçi bir yapıdan bahsedilebilir. Profildeki fotoğrafların teknik kalitesi, içeriğin niteliği, yazımın akıcılığı gibi unsurlar ekonomik ve kültürel sermayesi yüksek antrenörlerin profillerini daha izlenir kılmaktadır. Ancak simgesel sermayenin izleyicinin habitusu bağlamında şekillendiği düşünüldüğünde, farklı habitustan bireylerin erkeksi duruş ve sert ifadelere simgesel değer atfedebileceği söylenebilir. Yeni medya algoritmalarının kişiyi eğilimlerine göre yönlendirdiği düşünüldüğünde, her antrenöre onunla benzer düşüncede takipçiler yönlendirdiği ve bu nedenle de bütün antrenörlerin simgesel sermaye açısından Instagram sahnesinde görece eşit konumda bulundukları şeklinde bir yorumda bulunulabilir.

Sonuç olarak ise günümüzde bireylerin kimliklerini sürekli yeniden inşa etmek zorunda olduğu, bedenin de bu bağlamda bir projeye dönüştüğü, taşıyıcısına çeşitli avantajlar ve dezavantajlar getiren bir nesne konumuna evrildiği söylenebilir. Geleneksel medya ve Hollywood sinemasıyla gündelik yaşama giren vücut geliştirmenin sosyal medya ve özellikle Instagram'la yerini çok daha sağlamlaştırdığı ileri sürülebilir. Bu çalışma ağırlıklı olarak erkek kişisel antrenörlerin bedensel sermayelerini diğer sermaye tiplerine dönüştürme çabalarına odaklanmaktadır. Çalışma farklı bağlamlara taşınabilir; kadın antrenörler, antrenör olmayanlar ya da bedensel sermayesi düşük dezavantajı gruplar üzerine yapılacak olan çalışmalara fikir verebilir.

\section{KAYNAKÇA}

Akgün, E. (2019). Sosyal medya platformlarından youtube üzerinden benlik sunumunun dramaturjik bir analizi. Yeni Medya, 4, 29-49.

Alexander, M. (2003). Stylish hard bodies: Branded masculinity in Men's Health Magazine. Sociological Perspectives. Sociological Perspectives, 46(4):535-554.

Anderson, C., John, O. P., Keltner, D., \& Kring, A. M. (2001). Who attains social status? 


\section{MEDIAJ}

Effects of personality and physical attractiveness in social groups. Journal of Personality and Social Psychology, 81, 116-132.

Anderson, J., \& Johansson, T. (2014). The fitness revolution: Historical transformations in the global gym and fitness culture. Sport Science Review, 23(3), 91-112.

Atabek, G., \& Atabek, Ü. (2007). Medya metinlerini çözümlemek: İ̧̧erik, göstergebilim ve söylem çözümleme yöntemleri. Ankara: Siyasal Kitabevi.

Barthes, R. (2003). Çağdaş söylenler. (T. Yücel, Çev.) İstanbul: Metis Yayınları.

Barthes, R. (1977). Image Music Text. London: Fontana Press.

Barthes, R. (1993). Gösergebilimsel Serüven. İstanbul: Yapı Kredi Yayınları.

Baudrillard, J. (2015). Şeytana satılan ruh ya da kötülüğün egemenliği. (O. Adanır, Çev.) Ankara: Doğu Batı Yayınları.

Bauman, Z. (2012). Ölümlülük, ölümsüzlük ve diğer hayat stratejileri. (N. Demirdöven, Çev.) İstanbul: Ayrıntı Yayınları.

Bauman, Z. (2014). Parçalanmış hayat: Postmodern ahlak denemeleri. (i. Türkmen, Çev.) İstanbul: Ayrıntı Yayınları.

Bauman, Z. (2017). Akışkan modernite. İstanbul: Can Sanat Yayınları.

Bauman, Z., \& Lyon, D. (2013). Akışkan gözetim. (E. Yılmaz, Çev.) İstanbul: Ayrıntı Yayınları.

Baydur, M. (2010). Medyada "sağıılı" insan sunumları: Popüler kültürde sağlıklı ve sürdürülebilir yaşam görünümleri (Yayımlanmamış Yüksek Lisans Tezi). İstanbul: Marmara Üniversitesi Sosyal Bilimler Enstitüsü

Bircan, U. (2015). Roland Barthes ve göstergebilim. SBARD, 26, 17-41.

Bourdieu, P. (1986). The forms of capital. J. Richardson (Ed.) içinde, Handbook of theory and research for the sociology of education (s. 241-258). Westport CT: Greenwood.

Bourdieu, P. (2000). Pascalian meditations. Cambridge: Polity Press.

Bourdieu, P. (2010). Sermaye Biçimleri. M. M. Şahin, \& A. Ünal (Ed.) içinde, Sosyal Sermaye (s. 45-75). İstanbul: Değişim.

Bourdieu, P. (2014). Ayrım, beğeni yargısının toplumsal eleştirisi. (D. Fırat Şennan, \& A. G. Berkkurt, Çev.) Ankara: Heretik Yayıncılık.

Bourdieu, P., \& Wacquant, L. (2003). Düşünümsel bir antropoloji için cevaplar. İstanbul: iletişim Yayınları. 


\section{MEDIAJ}

Boyd, D. (2004). Friendster and publicly articulated social networking. Proceedings of the twenty-second annual SIGCHI conference on Human factors in computing systems New York. New York: ACM.

Boyd, D. (2006). Friends, friendster and MySpace top 8: Writing community into being on. Peer Reviewed Journal on The Internet, 11(12).

Boyd, D. (2007). Why youth (heart) social network sites: The role of networked publics in teenage social life. D. Buckingham (Ed.) içinde, Youth, Identity, and Digital Media (s. 119-142). Cambridge: MIT Press.

Castells, M. (2008). Ağ toplumunun yükselişi. İstanbul: Bilgi Üniversitesi Yayınları.

Chapman, D. L. (1994). Sandow the magnificent Eugen Sandow and the beginning of bodybuilding. Chicago: University of Illinois Press.

Cohan, S., Hark, i. (1993). Screening the male exploring masculinities in Hollywood Cinema. London: Routledge.

Çarpar, M. C., \& Gönç Şavran, T. (2019). Beden, kültür ve erkeklik: Vücut geliştirmenin eril bir alan olarak savunulması üzerine sosyolojik bir çalışma. Spor Bilimleri Araştırmaları Dergisi, $4(2), 264-288$.

Çurmagil, B. (1999). Osmanlı Devleti'nin Kuruluşunun 700. Yılı Münasebetiyle "Osmanlıda Spor" Sempozyumu. Ankara: Kültür Bakanlığı Yayınları.

Dalbay, R. (2018). Kimlik ve toplumsal kimlik kavramı. Süleyman Demirel Üniversitesi Sosyal Bilimler Enstitüsü Dergisi, 31, 161-176.

Debord, G. (2014). Gösteri Toplumu. İstanbul: Ayrıntı Yayınları.

Donath, J. S. (1998). Identity and deception in the virtual community. P. Kollock, \& M. Smith (Ed.) içinde, Communities in Cyberspace (s. 2-26). London: Routledge.

Donath, J. S., \& Boyd, D. (2004). Public displays of connection. BT Technology Journal, 22, 71-82.

Emir, E., Karaçam, M., \& Koca, C. (2016). Kadın boksörler: Boks ringinde ve ringin dışında sürekli eldiven giymek. Spor Bilimleri Dergisi, 26(4), 136-153.

Erdoğan, i. (2011). Erkek dergilerinde (Men's Health, FHM, Esquire Türkiye örneğinde) hegemonik erkek(lik), beden politikaları ve yeni erkek imajı, i. Erdoğan (Ed.) içinde Medyada hegemonik erkek(lik) ve temsil. İstanbul: Kalkedon Yayınları.

Ertürk, Y. (2016). Analysıs of the relationship between self-esteem and levels of narcissism through selfies of instagram users. AJIT-e: Bilişim Teknolojileri Online Dergisi, 7(24), 29-50. 


\section{MEDIIAJ}

Featherstone, M. (1982). The body in consumer culture. Theory, Culture \& Society, 1(2), 18-33.

Featherstone, M. (2010). Body, image and affect in consumer culture. Body \& Society, 16(1), 193-221.

Featherstone, M. (2013). Postmodernizm ve tüketim kültürü. (M. Küçük, Çev.) İstanbul: Ayrıntı Yayınları.

Foucault, M. (2003). iktidarın gözü. (ı. Ergüden, Çev.) İstanbul: Ayrıntı Yayınları.

Frew, M., \& Mcgillivray, D. (2005). Health clubs and body politics: Aesthetics and the quest for physical capital. Leisure Studies, 24(2), 161-175.

Genç, T. (1991). Toplumsal iş bölümü. Eğitim ve Bilim, 15(80), 48-56.

George, M. (2008). Interactions in expert service work: Demonstrating professionalism in personal training. Journal of Contemporary Ethnography, 37(1), 108-131.

Giddens, A. (2012). Sosyoloji. İstanbul: Kırmızı Yayınları.

Goffman, E. (2014). Günlük yaşamda benliğin sunumu. İstanbul: Metis Yayınları.

Göker, E. (2007). Ocak ve zanaat: Pierre Bourdieu derlemesi. İstanbul: Iletişim Yayınları.

Gölbaşı, H. (2018). Osmanlı devleti'nde spor tekkeleri. Iğdır Üniversitesi Sosyal Bilimler Dergisi, 15, 41-53.

Grant, M. (1964). The birth of western civilization: Greece and Rome. New York: McGrawHill.

Hall, S. (2000). Yeni Zamanların Anlamı. J. Martin, \& S. Hall (Ed.) içinde, Yeni Zamanlar. İstanbul: Ayrıntı Yayınları.

Harris, H. A. (1972). Sport in Greece and Rome. New York: Cornell University Press.

Harvey, G., Vachhani, S., \& Williams, A. (2014). Working out: Aesthetic labour, affect and the fitness industry personal trainer. Leisure Studies, 33(5), 454-470.

Heffernan, C. (2015). The history of Gold's Gym. Physicalculturestudy, https://physicalculturestudy.com/2015/04/30/the-history-of-golds-gym/

Hewitt, A., \& Forte, A. (2006). Crossing boundaries: Identity management and student/faculty relationships on the Facebook. Banff: CSCW.

Hogan, B. (2010). The presentation of self in the age of social media: Distinguishing performances and exhibitions online. Bulletin of Science Technology \& Society, 377-386. 
Hutson, D. (2013, Augst). Your body is your business card: Bodily capital and health authority in the fitness industry. Social Science \& Medicine, 90, 63-71.

James, W., Miller, G. (2007). The Principles of Psychology. Cambridge: Harvard University Press.

Johansson, T., \& Andreasson, J. (2014). The fitness revolution: Historical transformations in the global gym and fitness culture. Sport Science Review, 23(3-4), 91-112.

Johansson, T., \& Andreasson, J. (2016). The gym and the beach: Globalization, situated bodies, and australian fitness. Journal of Contemporary Ethnography, 45(2), 143-167.

Johansson, T., Andreasson, J., \& Mattsson, C. (2017). From subcultures to common culture: bodybuilders, skinheads, and the normalization of the marginal. Sage Open, 1-9.

Kah, D., \& Scholz, P. (2004). Das hellenistische gymnasion. Berlin: Akademie-Verlag.

Kant, I. (2020). "Aydınlanma nedir?" sorusuna yanıt. www.istabip.org.tr: https://www.istabip.org.tr/site_icerik/2017/haberler/kasim/aydinlanma_nedir_kant.pdf

Karaçam, M. Ş., \& Koca, C. (2016). Bedenden hiyerarşiye uzanan bir erkekleşme süreci olarak vücut geliştirme(k). C. Koca (Ed.) içinde, Sporun Toplumsal Cinsiyet Halleri (s. 116-133). Ankara: Spor.

Kavut, S. (2018). Goffman'ın benlik sunumu kuramı bağlamında sosyal medyada kimlik inşası: Instagram üzerine bir araştırma. Nosyon: International Journal of Society and Culture Studies, 1, 1-12.

Kearney, R. (2003). Modern movements in European philosophy. Manchester: Manchester University Press.

Kellner, D. (2004). Popüler kültür ve postmodern kimliklerin inşası. Doğu Batı Düşünce Dergisi, 15, 187-220.

Kıral, B. (2020). Nitel bir veri analizi yöntemi olarak doküman analizi. Sosyal Bilimler Enstitüsu Dergisi, 15, 170-189.

Lewis, K., Kaufman, J., \& Christakis, N. (2008). The taste for privacy: An analysis of college student privacy settings in an online social network. Journal of Computer-Mediated Communication, 14, 79-100.

Lynn, D. (2012). Men's-YMCA. The Oxford Encyclopedia of American Social History (Cilt 2, s. 547). içinde Oxford: Oxford University Press.

Lyotard, J. F. (1997). Postmodern durum. (A. Çiğdem, Çev.) Ankara: Vadi Yayınları.

Maguire, S. J. (2008). The personal is professional: Personal trainers as a case study of 


\section{MEDIAJ}

cultural intermediaries. International Journal of Cultural Studies, 11(2), 211-229.

Manovich, L. (2001). The language of new media. Cambridge: Mass: MIT Press.

Marshall, C., \& Rossman, G. (2014). Designing qualitative research. New York: Sage Puplications. Yayınları.

McLuhan, M. (2014). Gutengerg galaksisi tipografik insanın oluşumu. İstanbul: YKY

Mead, G. H. (1972). Mind, self, and society. Chicago: University of Chicago Press.

Mears, A. (2015). Girls as elite distinction: The appropriation of bodily capital. Poetics, 53, 22-37.

Meder, M., \& Çeğin, G. (2011). Bourdieu'yü okumak: Post-pozitivist bir sosyolojinin imkânı üzerine, Gaziantep Üniversitesi Sosyal Bilimler Dergisi, 10(1), 233-256.

Mendelson, A., \& Papacharissi, Z. (2010). Look at us: Collective narcissism in college. Z. Papacharissi (Ed.) içinde, The networked self: Identity, community and culture on social network sites (s. 251-273). London: Routledge.

Merriam, S. B. (2009). Qualitative research. A guide to design and implementation. San Francisco: John Wiley-Sons.

Misci Kip, S. (2010). Kültürel sermaye ve televizyon izleme alışkanlıkları (Yayımlanmamış Doktora Tezi). İzmir: Ege Üniversitesi Sosyal Bilimler Enstitüsü.

Monaghan. (2010). Bodybuilders drugs and risk health, risk and society. New York: Routledge.

Monaghan, L. (2001). Bodybuilders drugs and risk health, risk and society. New York: Routledge.

Mora, N. (2008). Medya ve kültürel kimlik, Uluslararası Insan Bilimleri Dergisi, 5(1), 1-14.

Oskay, Ü. (2016). Kitle iletişimi açısından toplumsal egemenlik ve kültürel donanımları. Kurgu Anadolu Üniversitesi Iletişim Bilimleri Fakültesi Uluslararası Hakemli Illetişim Dergisi, 3(3), 29-100.

Oxford Dictionary. (2020). oxfordlearnersdictionaries:

https://www.oxfordlearnersdictionaries.com/definition/english/fitness?q=fitness

Öztürk, A. (2012). Eril bedenselleşme: Hegemonik erkek bedenin inşası. FLSF (Felsefe ve Sosyal Bilimler Dergisi), (13), 39-53.

Pedersen, P., \& Tjørnhøj-Thomsen, T. (2017). Bodywork and bodily capital among youth 


\section{MEDIAJ}

using fitness gyms. Journal of Youth Studies, 20(4), 430-445.

Reich, D. (2010). The world's most perfectly developed man. Charles Atlas, physical culture, and the inscription of American masculinity. Men and Masculinities, 9, 444-461.

Ritzer, G., \& Jurgenson, N. (2010). Production, consumption, prosumption. Journal of Consumer Culture, 10(1), 13-36.

Robinson, L. (2007). The cyberself: The self-ing project goes online, symbolic interaction. New Media \& Society, 9, 93-110.

Sassatelli, R. (1999). Interaction order and beyond: A field analysis of body culture within fitness gyms. Body \& Society, 5(2), 227-248.

Schroeder, R. (2002). The social life of avatars: Presence and interaction in shared virtual environments. R. Schroeder (Ed.) içinde, Social interaction in Virtual Environments: Key issues, Common Themes, and a Framework for Research (s. 1-18). Berlin: Springer-Verlag.

Shilling, C. (1993). The body and social Theory. London: Sage Publications.

Soydaş, N., \& Tandaç Güneş, N. (2020). Gündelik hayatta benlik sunumunun dijital oyunlar üzerinden incelenmesi, IBAD Sosyal Bilimler Dergisi, 7, 235-252.

Stewart, B., Smith, A., \& Moroney, B. (2013). Capital building through gym work. Leisure Studies, 32(5), 542-560.

TDK. (2020). sozluk.gov.tr: https://sozluk.gov.tr/

Turner, B. (1992). Regulating bodies: Essays in medical sociology. London: Routledge.

Ulutaş, B. (2017). Doküman Analizi. F. N. Seggie, Y. Bayyurt (Ed) içinde, Nitel Araştırma Yöntem, Teknik, Analiz ve Yaklaşımları. Ankara: Anı Yayıncılık.

Ünal, A. (2017). Bourdieu'nün tabakalaşma teorisi bağlamında üst sınıftan alt sınıfa doğru tahakkümü. Uluslararası Sosyal Araştırmalar Dergisi, 10(49), 380-388.

Wacquant, L. (19995). Pugs at work: Bodily capital and bodily labour among professional. Body \& Society.

Yumul, A. (2000). Bitmemiş Bir Proje Olarak Beden. Toplum ve Bilim, 84, 37-49.

Yücel, Y. (2019). Sağlık ve Fitness Söylemi İçerisinde Kadın ve Erkek Bedenleri: Women's Health ve Men's Health Dergisi Örneği. Galatasaray Üniversitesi Iletişim Dergisi, 30, 215-241. 